\title{
Effect of ultraviolet radiation (UVR) on the life stages of fish
}

\author{
Ricardo N. Alves $\cdot$ Susana Agustí
}

Received: 31 August 2019/Accepted: 24 April 2020/Published online: 9 May 2020

(C) The Author(s) 2020

\begin{abstract}
Current levels of Ultraviolet Radiation (UVR) represent a significant threat to many fish species. The first studies on the effects of UVR on organisms were performed on fish at the beginning of the twentieth century, and the topic has been progressing continuously until the present. Here, we review the reported harmful effects of ultraviolet $\mathrm{B}$ (UVB) and A (UVA) radiations in fish at different lifecycle stages, including embryo, larvae, juveniles and adults. The most evident negative effects during the early development stages are an increase in mortality and incidence in developmental malformations, with the skin and gills the most affected tissues in larvae. Growth reduction, a loss in body condition, and behavioral, physiological and metabolic changes in juveniles/adults occur under short- or long-term UVB exposure. The skin in juveniles/adults undergoes profound morphological and functional changes, even after acute exposure to UVR. Impairment of molecular and cellular processes was evidenced in all development stages by increasing the levels of DNA damage, apoptosis and changing tissues' antioxidant status. The different photo-protective mechanisms to cope
\end{abstract}

R. N. Alves $(\bowtie) \cdot$ S. Agustí

Red Sea Research Center (RSRC), King Abdullah

University of Science and Technology (KAUST),

Thuwal 23955, Saudi Arabia

e-mail: ricardo.alves@kaust.edu.sa

S. Agustí

e-mail: susana.agusti@kaust.edu.sa with excessive UVR exposure are also revised. Currently, stratospheric ozone dynamics and climate change interact strongly, enhancing the potential exposure of fish to UVR under water. Due to these environmental changes, fish are exposed to new and complex interactions between UVR and environmental stressors, which potentially affects fish growth and survival. Understanding the ability of fish to cope and adapt to these environmental changes will be essential to evaluate the potential impact in fisheries and mitigate ecological problems.

Keywords Ultraviolet radiation - Harmful effects . Fish $\cdot$ Life stages

\section{Introduction}

Solar energy reaching the earth's surface includes ultraviolet radiation (UVR) that can be divided into three spectral bands: ultraviolet $\mathrm{C}$, highly harmful (UVC, 200-280 nm; mostly absorbed by stratospheric ozone and oxygen; does not reach the earth's surface); ultraviolet $\mathrm{B}$, highly energetic and moderately harmful (UVB, 280-320); and ultraviolet A, mildly energetic and less harmful (UVA, 320-400 nm) (Madronich et al. 1995; McKenzie et al. 2007).

In the aquatic environment, both UVA and UVB radiation bands can penetrate the water column, showing variable attenuation across saltwater and 
freshwater ecosystems both seasonally and geographically. Dissolved organic matter and suspended particles are the major components that contribute to the attenuation of light under water. UVR is largely absorbed by chromophoric dissolved organic matter, which consequently reduces the exposure of aquatic organisms to UVR (reviewed by Häder et al. 2007; Williamson et al. 1996; Zagarese and Williamson 2001). Short UVR wavelengths are strongly absorbed under water, and UVB radiation is highly attenuated, penetrating from only a few centimeters below the surface in turbid lakes to more than 20 meters in transparent oceanic waters (Huovinen and Goldman 2000; Huovinen et al. 2003; Michael et al. 2012; Tedetti and Sempere 2006). UVA wavelengths are less attenuated than UVB, penetrating deeper into the water column, reaching depths greater than $70 \mathrm{~m}$ (Schlichter et al. 1986; Tedetti and Sempere 2006). Nonetheless, the significant depletion of stratospheric ozone due to anthropogenic emissions of atmospheric pollutants has enhanced the UVB radiation that reaches the biosphere (Barnes et al. 2019; Crutzen and Arnold 1986; Molina and Rowland 1974; Rowland 2006; Rowland and Molina 1975), causing detrimental effects to aquatic organisms and ecosystems (Häder et al. 1998; Helbling et al. 2003; Llabrés and Agustí 2006, 2010; Llabrés et al. 2013).

Current levels of UVA and UVB radiation in aquatic ecosystems can cause damage at different levels to a broad range of organisms, from bacteria to higher vertebrates (reviewed by Häder et al. 2007, 2011, 2015; Llabrés et al. 2013; Peng et al. 2017; Williamson et al. 2019; Xiao et al. 2015). UVR is mutagenic and is considered a strong evolutionary selective force in organisms (Rothschild 1999; Rozema et al. 2002). A meta-analysis study observed that aquatic organisms from the Northern Hemisphere tend to be more susceptible to the effects of UVB than those from the Southern Hemisphere, due to strong stratospheric ozone asymmetries between the hemispheres (Agustí et al. 2015).

In the early 1930s, the harmful effects of exposure to UVR during embryonic development were reported for the first time in fish (Hinrichs and Genther 1931). A considerable number of Fundulus heteroclitus fertilized eggs and early embryos exposed to UVR exhibited severe degrees of axial duplication and showed several abnormalities including poor eye development (Hinrichs and Genther 1931; Hinrichs
1938). A few years later, Bell and Hoar (1950) observed high mortality in sockeye salmon (Oncorhynchus nerka) fertilized eggs in the later stages of development and larvae that had been exposed to UVR. These authors also noticed several skin lesions in the sockeye salmon larvae after UV exposure including the displacement between the epidermis and the basement membrane, loss of scales and disruption of the mucous producing cells (Bell and Hoar 1950).

The early development stages appear to be the lifecycle stages that are most prone to damage (Dahms and Lee 2010); however, the tolerance of juveniles and adult fish to UVR exposure has also been studied, and many species appear to be highly sensitive to both UVA and UVB radiation at later development stages in their lifecycle (García-Huidobro et al. 2017; Jokinen et al. 2008; Kazerouni et al. 2017; Rick et al. 2014; Sayed et al. 2016). Reduction in growth, impaired development, changes in behavior, development of skin and eye lesions, suppression of the immune system, reduction on diseases resistance, DNA damage and a series of metabolic and physiological stress changes are some of the described effects of UVR exposure in fish (Browman et al. 2003; Hunter et al. 1981; Salo et al. 2000a; Sandrini et al. 2009; Sharma et al. 2005). Many fertilized eggs and larvae, as well as visual predators, herbivores and farmed fish obligated to live at the photic surface layer, are potentially exposed to significant UVR radiation. From an economic point of view, several cases of sunburn due to overexposure to high natural solar radiation resulted in numerous losses in aquaculture fish farms during the 1980-1990s, particularly in those where the fish were grown in outdoor tanks (Bullock 1982, 1984, 1988; Bullock and Coutts 1985; Lowe and GoodmanLowe 1996).

Although fish species can develop several strategies to cope with the harmful effects of UVR (e.g., the avoidance of UV, production of UV-absorbing compounds and DNA damage repairing mechanisms), recent meta-analyses continue to corroborate the negative effects of UVR on aquatic organisms (Braun et al. 2016; Williamson et al. 2019). During the past decade, many reviews have addressed the effects of UVR on aquatic ecosystems, mainly on primary producers, zooplankton and invertebrates. To the best of our knowledge, there are still few literature reviews, specifically compiling the effects of UVR effects. The effects of UVR on fish has been reviewed briefly as 
part of broader general reviews on the topic (Barnes et al. 2019; Häder et al. 2007, 2011, 2015), or has been reviewed more specifically such was done by Zagarese and Williamson (2001). Recently, Lawrence et al. (2019) revised the impact of UVR exposure in the fish immune system and mentioned that UVR exposure could have a negative effect on the immune control of infection by some fish species, especially in the case of fish produced by aquaculture. These authors also described some of the photoprotective mechanisms used by some, but not all fish species, which help to mitigate the negative impacts of UVR exposure. However, more recent reviews considering other adverse effects and analyzing results collected over the last two decades do not yet exist. Our goal here is to review the literature and recent studies describing the harmful effects of UVR on both marine and freshwater fish species. We also review the effect of different exposure periods (acute, short-term, or long-term exposure) and the mechanisms developed by fish organisms to cope with the effects of UVR. Lastly, we revise recent studies that address the interaction between the harmful effects of UVR and environmental stressors, like climate change or pollutants.

\section{Detrimental effects of UVR on fish}

Early development stages: embryos and larvae

\section{Increase of mortality, developmental abnormalities, behavioral and metabolic changes}

During early development, both fresh and seawater fish are sensitive to UVR. The most evident effects of UVR (mainly UVB) exposure are the reduction of survival rates and the increase in the number and types of developmental malformations in both embryos and larvae, when exposed to an acute dose, or for a shortand long-term exposure period. Subsequently, these developmental abnormalities have been associated with high mortality after UVR exposure (e.g., Dong et al. 2007; Lesser et al. 2001; Mahmoud et al. 2009; Vásquez et al. 2016) (Tables 1 and 2, see summary in Fig. 1).

$4 \mathrm{~h}$ post-fertilization (hpf) zebrafish (Danio rerio) embryos exposed for $2.4 \mathrm{~h}$ (UVB, $295 \mathrm{~nm}$ cutoff) showed a reduction of more than $50 \%$ in their survival rate after 6 days, with a high incidence of developmental abnormalities, including caudal (posterior) notochord torsion and bending (Nuñez et al. 2012). In the same species, embryos during the midgastrula stage of development (6-7 hpf) exposed to $31.1 \mathrm{~kJ} \mathrm{~m}^{-2} \mathrm{UVB}$ radiation had mortality rates higher than $70 \%$ (Dong et al. 2007). Lower hatching rates and several embryonic malformations, such as enlarged pericardial sacs, spinal deformities and minor spinal bending, also occurred after UVB exposure (Dong et al. 2007). Woundfin (Plagopterus argentissimus) embryos are sensitive even to low levels of UVB radiation $\left(0.15 \mathrm{~W} \mathrm{~m}^{-2}\right)$ when exposed for longer periods $(14.5 \mathrm{~h})$. These UVB levels correspond to $25 \%$ of the ambient irradiance observed in the bubbling ponds of some fish hatcheries in Arizona, where no embryo survival was measured after UVB exposure (Holmquist et al. 2014). The penetration of UVR in the water column depends on several variables such as the incident irradiance, optical properties of the water itself, phytoplankton, concentration of dissolved organic matter, and density of suspended particles. Noteworthy, the most significant factors modulating the UVR attenuation in the water column are the chlorophyll a and the chromophoric dissolved organic matter (reviewed by Häder et al. 2007, 2011). The amount of dissolved organic matter together with the nest location/depth choice can have an important role in the spawning success and embryotic survival of some fish species, such as the case of the bluegill sunfish (Lepomis macrochirus) in the lakes Tahoe (California-Nevada border, USA) and Giles (Pennsylvania, USA), (Olson et al. 2006, 2008; Tucker et al. 2010). In surface waters of the Lake Tahoe with low dissolved organic carbon concentrations (high UVB transparency, $22.65 \mathrm{~kJ} \mathrm{~m}^{-2}$ ), almost $90 \%$ of the bluegill larvae died after 4 days of UVR exposure. Still, only $15 \%$ of the larvae died in the surface waters showing high dissolved organic carbon concentrations (low UVB transparency, $0.60 \mathrm{~kJ} \mathrm{~m}^{-2}$ ), (Tucker et al. 2010). Little information is available on the effects of UVA radiation on freshwater embryos. For example, Japanese medaka (Oryzias latipes) fertilized eggs (4 cell stage) showed high resistance to different UVA radiation levels. Nevertheless, the number of resulting deformed embryos increased and the hatching time was prolonged with an increase in UVA dose (Sayed and Mitani 2017). An increased hatching time was also noticed in zebrafish embryos when exposed to UVB radiation (Dong et al. 2007). 


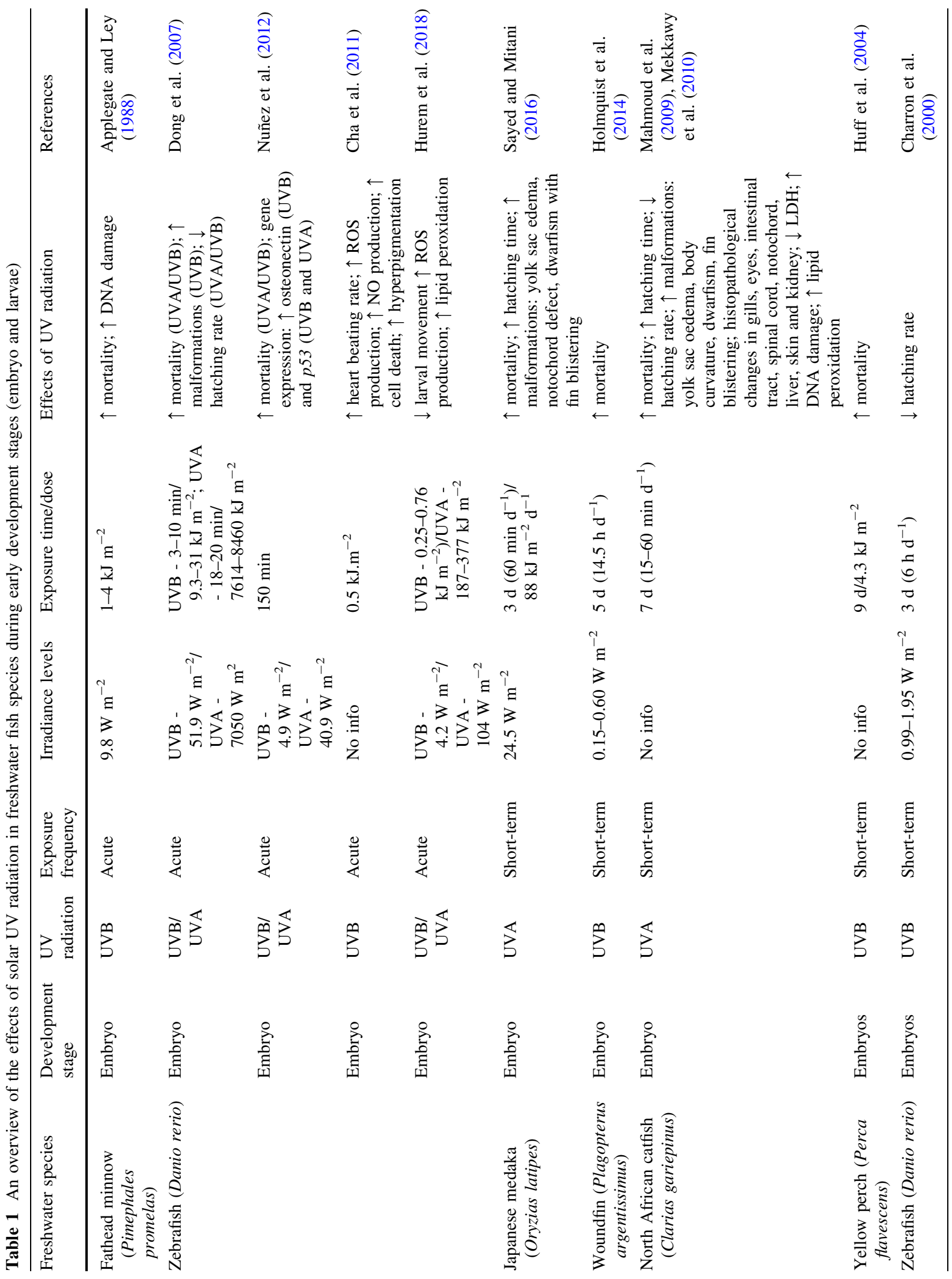




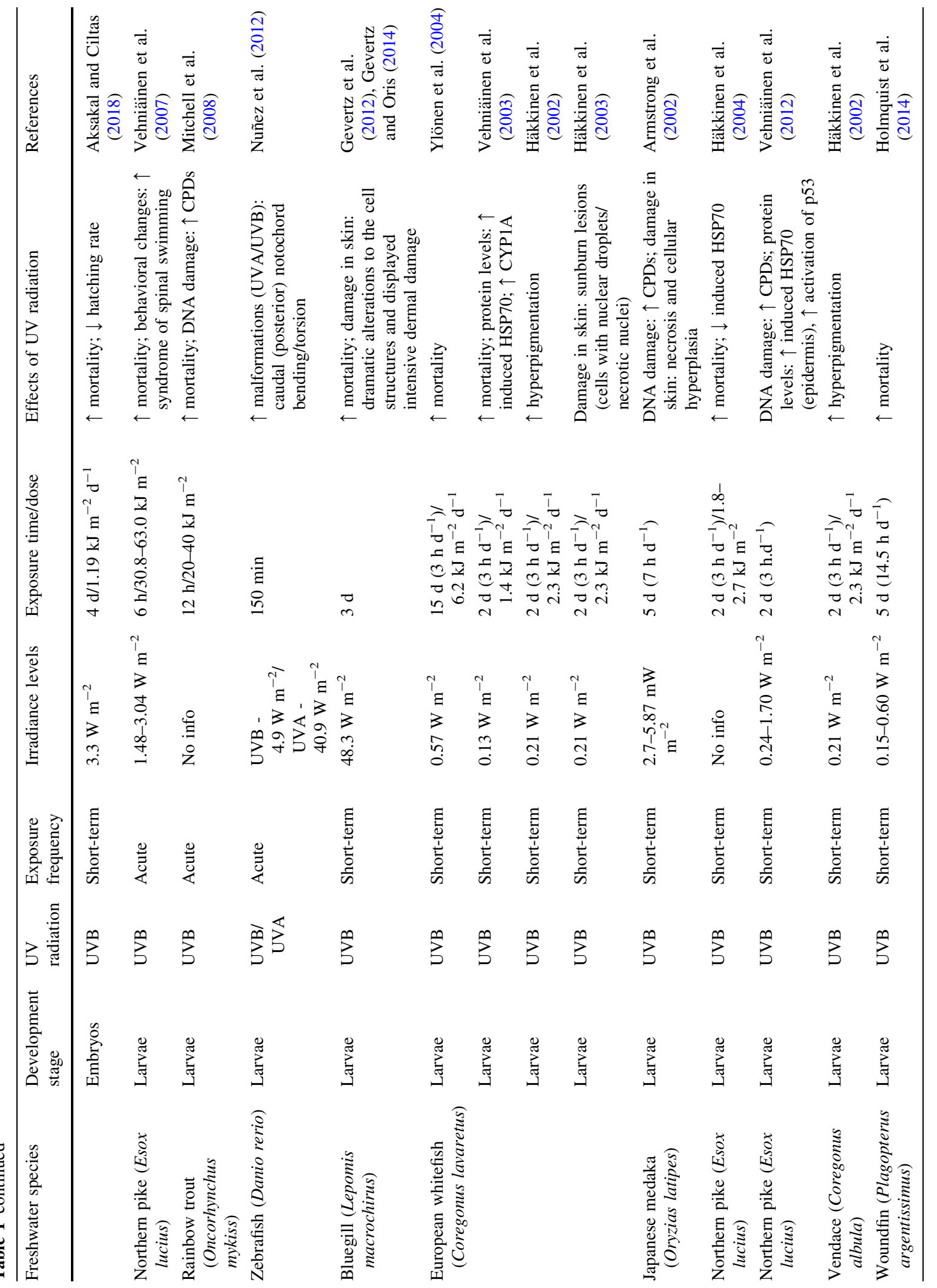




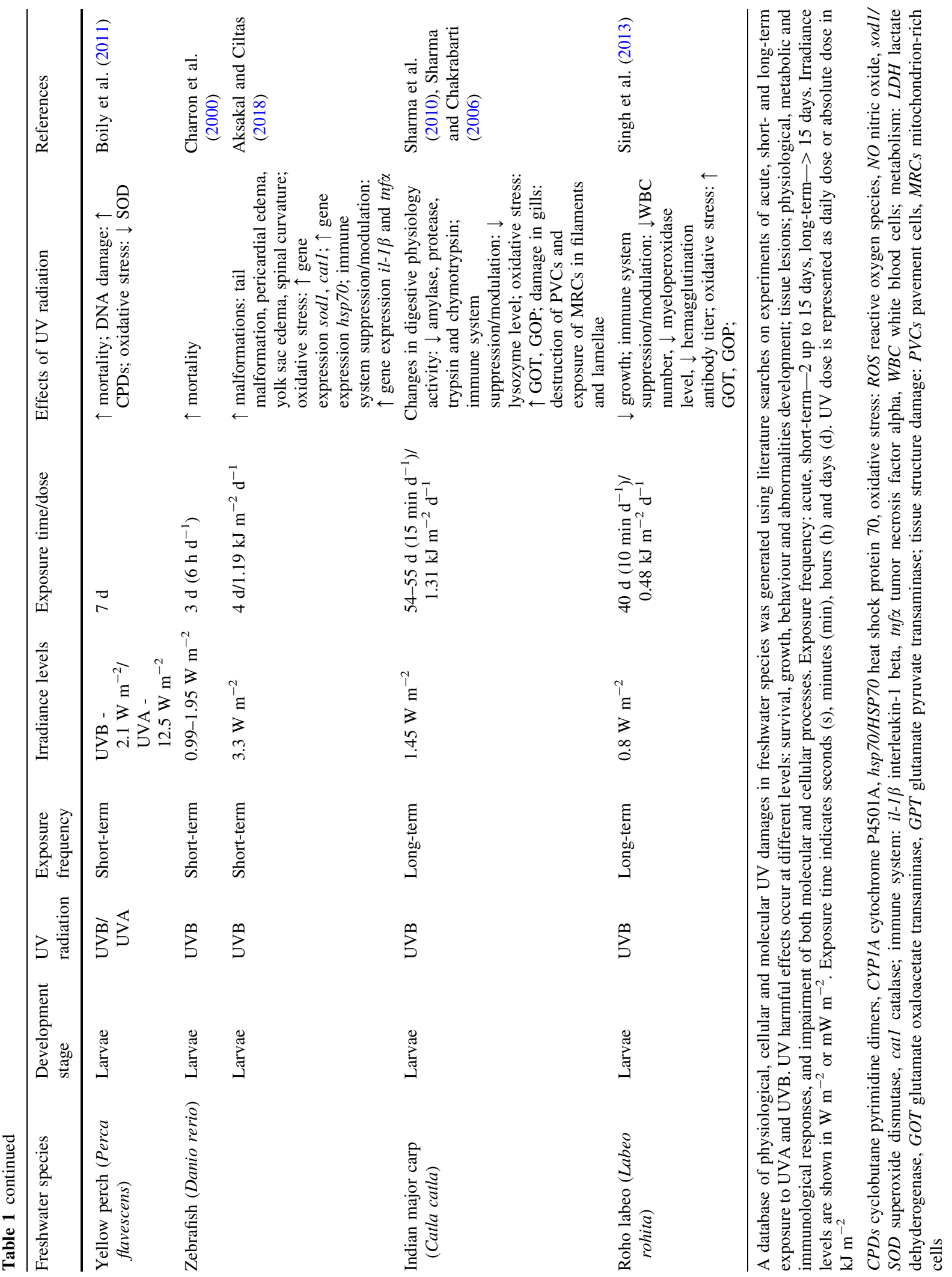




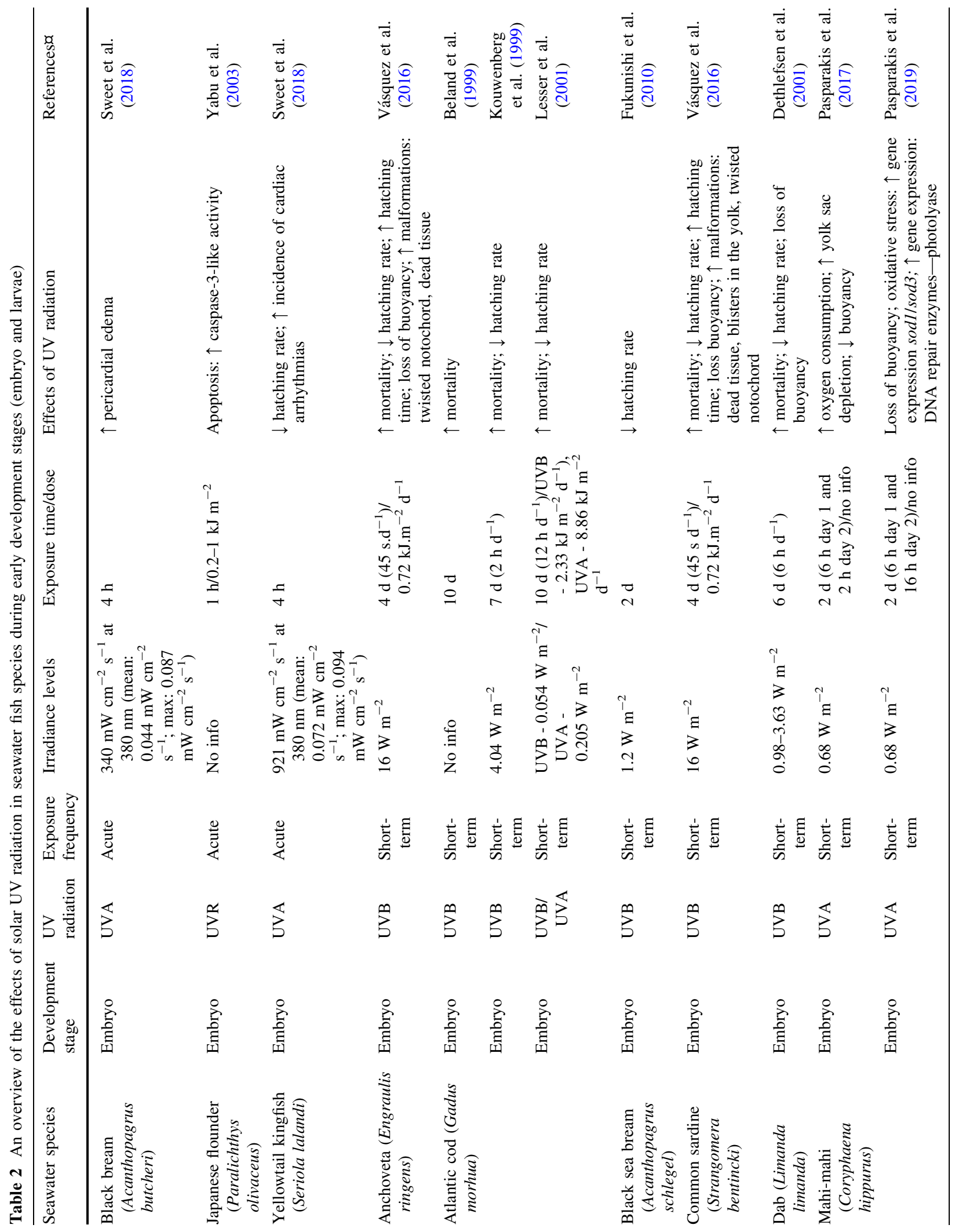




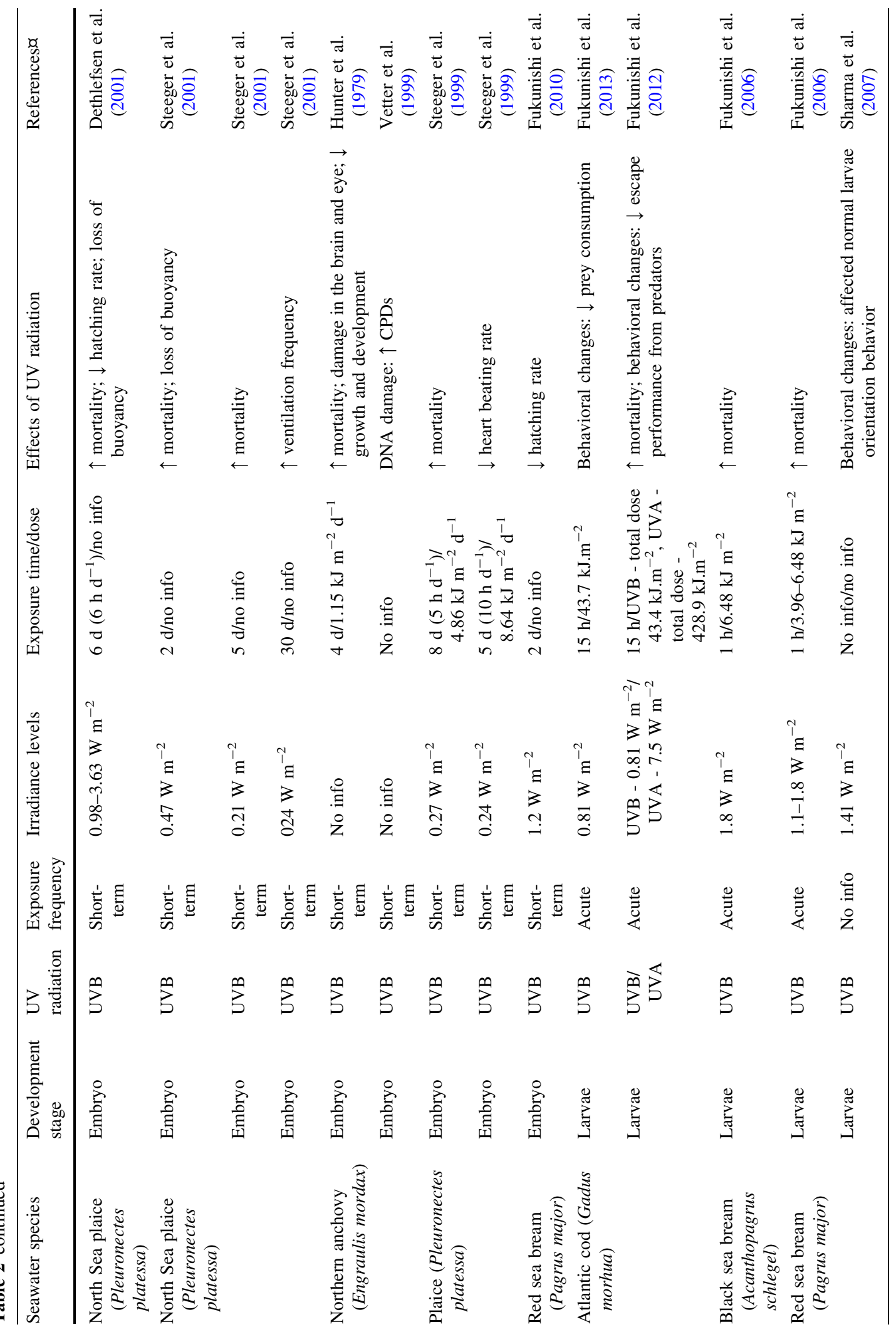




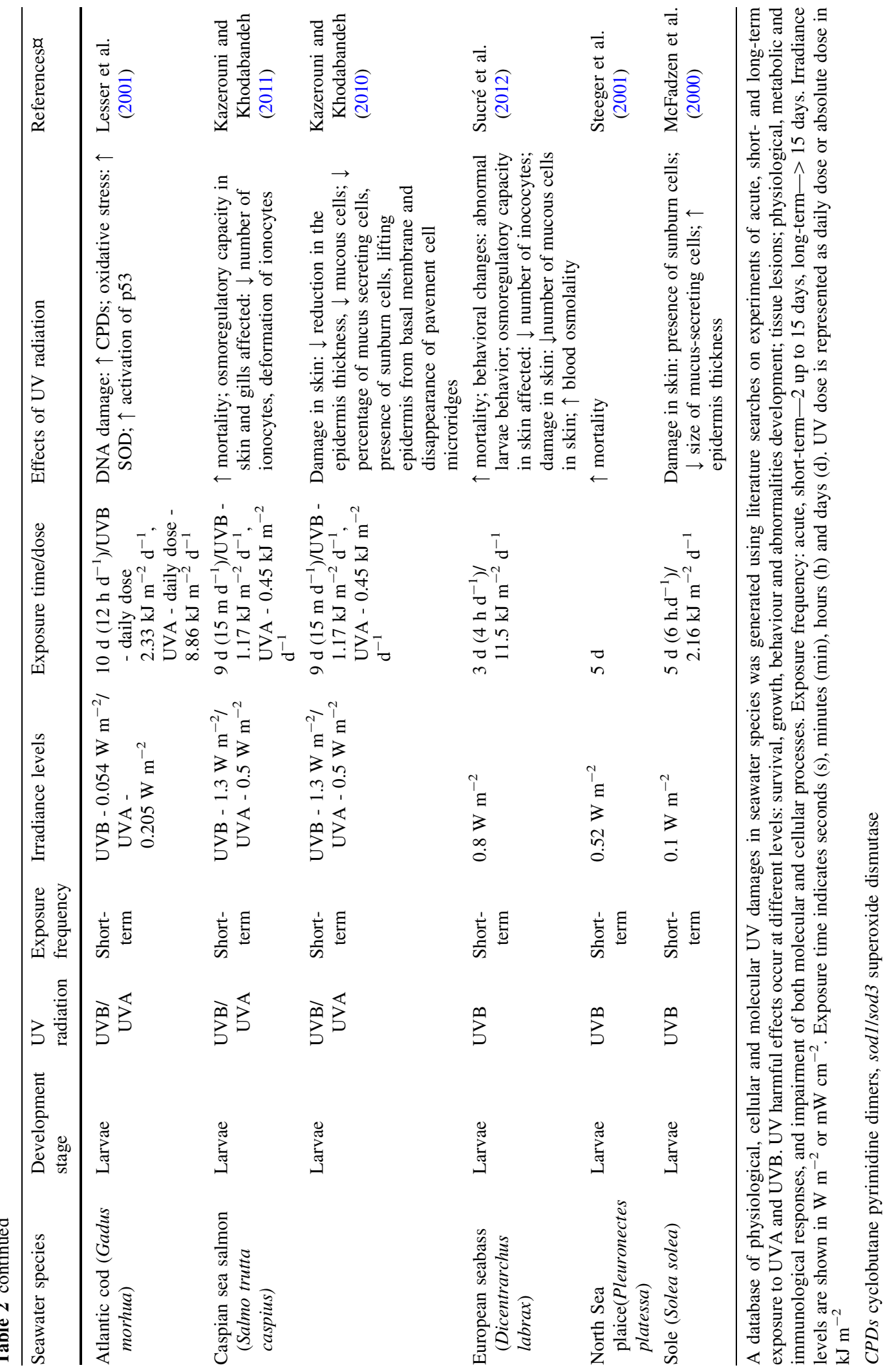




\section{(A) Survival, growth and development}

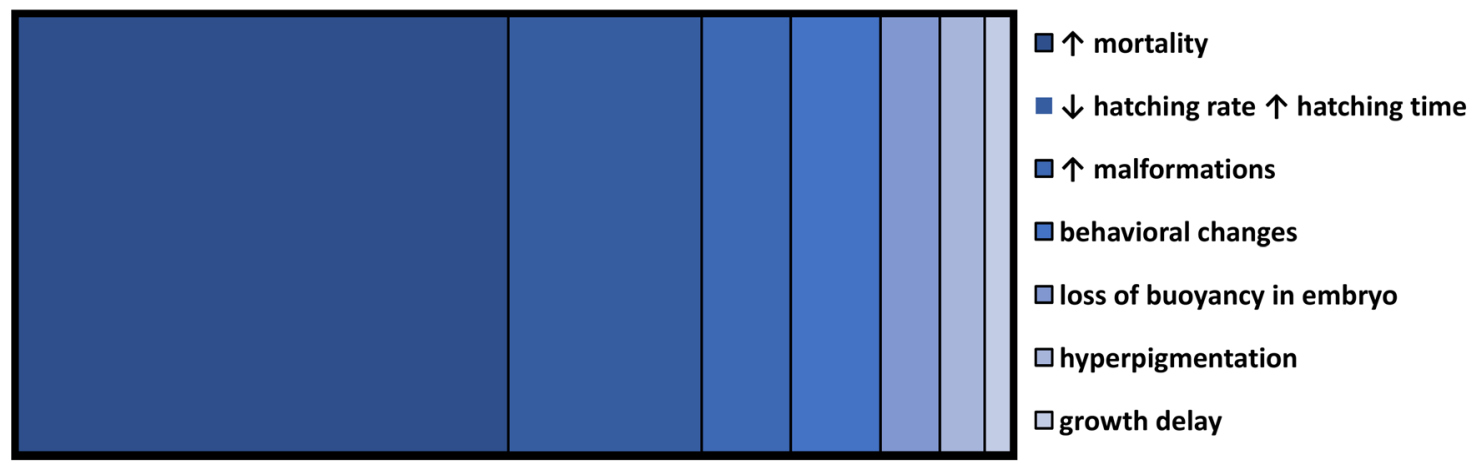

\section{(B) Tissue lesions, physiological, immunological and metabolic changes Impairment of molecular and cellular processes}

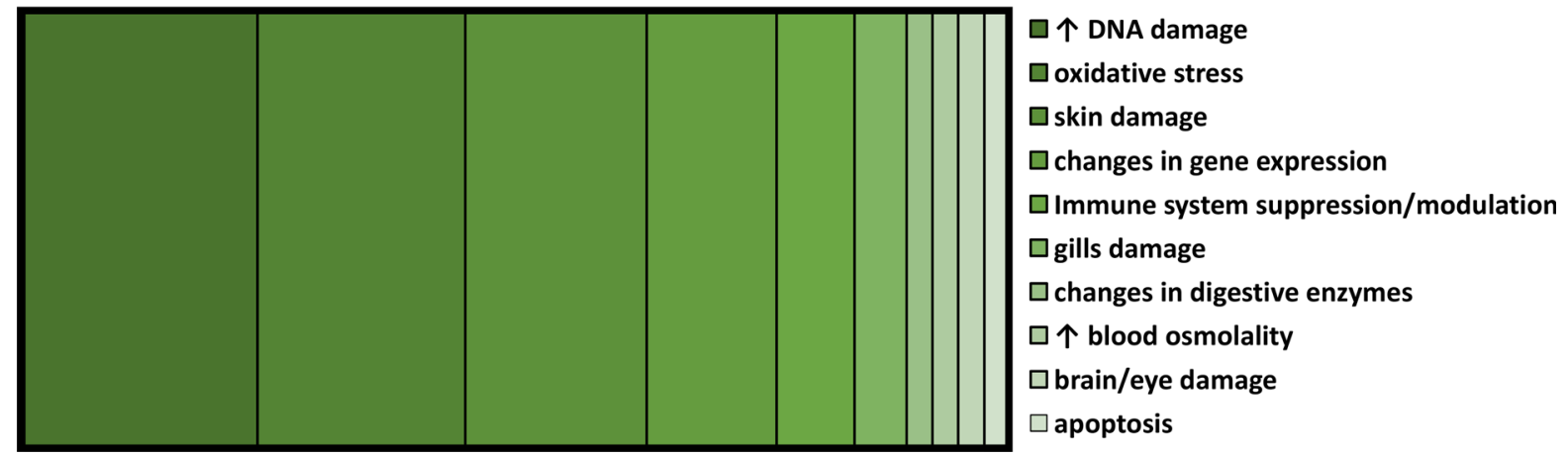

Fig. 1 Summary of the current knowledge regarding the adverse effects of UVR in fish during early development (embryo and larvae). a Effects on survival, growth and development of body malformations and b tissues lesions, physiological, immunological and metabolic changes, including

Survival rates in the early stages of the seawater fish species, Atlantic cod (Gadus morhua), red seabream (Pagrus major), dab (Limanda limanda), North Sea plaice (Pleuronectes platessa), and northern anchovy (Engraulius mordax) are also affected by UVB radiation (Beland et al. 1999; Dethlefsen et al. 2001; Hunter et al. 1979, 1981; Steeger et al. 2001), (Table 2). The UVB sensitivity of North Sea plaice depends on the timing of radiation exposure during embryonic development. No embryo survival was observed if the exposure to UVB radiation occurred at the early embryonic stage Ib, whereas no differences in survival were observed between non-irradiated and UV exposed gastrulation stage II embryos (Steeger et al. 1999). In Atlantic cod, more than 50\% of the impairment of molecular and cellular processes. The color intensity represents the number of studies reporting each detrimental effect, in which the stronger the color/bar size the higher the number of references for each detrimental effect

fertilized eggs died after $32 \mathrm{~h}$ of exposure to UVB $\left(4.04 \mathrm{~W} \mathrm{~m}^{-2}\right.$ ) under ozone layer depletion (around $20 \%$ ) conditions (Kouwenberg et al. 1999). Dethlefsen et al. (2001) demonstrated that increasing levels of UVB as a consequence of ozone depletion (reduction to 270 Dobson units, DU), resulted in high embryo mortality, a decrease in hatching rate and a loss of buoyancy in dab and North Sea plaice $24 \mathrm{hpf}$ exposed embryos. The embryonic development of North Sea plaice during spring spawning is not endangered by the actual UVB levels, or in the case of a reduction of 180DU. In Chile, actual levels of UVB observed in the Gulf of Arauco and Conception Bay are considered harmful to the planktonic anchoveta (Engraulis ringens) and common sardine (Strangomera 
bentincki). Embryos from both species at stages I (without embryo) and II (early embryo: embryo covers half of the chorion) were irradiated over 4 days, whereas embryos from stage III (late embryo: the embryo covers more than half of the chorion) were exposed over 3 days. Both species showed a decrease in hatching success, changes in buoyancy and the development of several malformations. Embryo abnormalities included blisters on the yolk at the earliest stages, twisting of the notochord at different levels of intensity in the most advanced stages, and the presence of dead tissue in all stages of development (Vásquez et al. 2016).

High variability on UVB tolerance during larval stages have been shown among fish species (Fukunishi et al. 2012; Mitchell et al. 2008; Sucré et al. 2012; Vehniäinen et al. 2012). Caspian Sea salmon (Salmo trutta caspius) larvae exposed to $0.5-1.3 \mathrm{~W} \mathrm{~m}^{-2}$ experienced $100 \%$ mortality after 9 days of exposure to UVR (Kazerouni and Khodabandeh 2011). Similar mortality levels were observed in woundfin larvae exposed to $0.15-0.60 \mathrm{~W} \mathrm{~m}^{-2}$ for $15 \mathrm{~h}$. Susceptibility of woundfin larvae to UVB radiation depends on the larvae development stage (Holmquist et al. 2014). Northern pike (Esox lucius) larvae subjected to daily doses of 1.8 and $2.7 \mathrm{~kJ} \mathrm{~m}^{-2}$ of UVB for 2 days, showed an increase in mortality by $10-20 \%$ (Häkkinen et al. 2004). In two sparidae species, black seabream (Spondyliosoma cantharus) larvae showed significantly higher survival rates than the red seabream larvae after exposing them to the same UVB conditions, suggesting that black seabream is probably better adapted to habitats with high UVB radiation than red seabream (Fukunishi et al. 2006). Short-term exposure in yellow perch showed that larval survival was inversely related to the UVR intensity dose, and similar results were obtained for exposure for 7 days for both UVA/UVB and UVA only (Boily et al. 2011). UVB negatively impacted the antipredator escape performance of Atlantic cod larvae exposed to a dose rate of UVB radiation $\left(2.9 \mathrm{~kJ} \mathrm{~m}^{-2} \mathrm{~h}^{-1}\right)$ for $15 \mathrm{~h}$, which led to higher predation mortality (Fukunishi et al. 2012). UVB induced atrophy in the European seabass (Dicentrarchus labrax) fin fold after 2 days of exposure resulting in the loss of its normal swimming capability. Such atrophy may have been caused by apoptosis or necrosis processes (Sucré et al. 2012). In addition, the orientation behavior of red seabream larvae changed after exposure to UVB, $1.41 \mathrm{~W} \mathrm{~m}^{-2}$.
The authors noticed that this species can develop UVB tolerance during ontogenic development (Sharma et al. 2007). After 4 days of exposure, only 50\% of northern anchovy larvae survived and they showed retarded growth and development, several lesions in the eyes and in the brain, and evident dispersion of pigment within melanophores (Hunter et al. 1979). A decrease in the specific growth rate of Roho labeo (Labeo rohita) was observed after 40 days of exposure to $0.80 \mathrm{~W} \mathrm{~m}^{-2}$ (Singh et al. 2013).

\section{Tissue lesions, physiological changes and immune system modulation}

During the early development stages, several tissues are exposed to the harmful effects of UVR and physiological changes and immune system modulation have been reported (Tables 1 and 2, see summary in Fig. 1). The occurrence of lesions in the skin and gills of larvae exposed to UVR have been reported in recent years. Microscopic examination of native Lahontan redside minnow (Richardsonius egregius) and non-native warm-water bluegill sunfish skin exposed to UVR revealed that the native species is more adapted to high UV conditions that are characteristic of the environment of the near shore Lake Tahoe (Gevertz and Oris 2014). The skin from bluegill sunfish exhibited greater damage in both epidermis (more irregular and thinner) and dermis (formation of extracellular space) and potential DNA damage and impairment of cellular respiratory processes (Gevertz and Oris 2014; Gevertz et al. 2012). In sole (Solea solea), larval skin is slightly pigmented, and five days of exposure to UVB $\left(2.15 \mathrm{~kJ} \mathrm{~m}^{-2} \mathrm{~d}^{-1}\right)$ resulted in the appearance of the characteristic sunburn because of damaged cells and a reduction in the size of the mucous producing cells. In contrast, the highly pigmented skin of the turbot (Scophthalmus maximus) larvae was not affected after exposure to the same UVB conditions (McFadzen et al. 2000). UVR led to the appearance of sunburn cells and a reduction in the epidermis thickness, as well as the number of mucous producing cells in Caspean Sea salmon. The disappearance of pavement cell microridges and a lifting of the epidermis from the basal membrane were observed in the UVR exposed larvae (Kazerouni and Khodabandeh 2010). In addition, UVR exposure resulted in ionocytes deformation as well as a reduction in their number and cell size. These mitochondrial-rich cells 
are important for osmoregulation, respiration and excretion functions in the skin, especially during early development, and the damage observed in these cells may have contributed to the high mortality observed after UV exposure (Kazerouni and Khodabandeh 2011). The loss of osmoregulatory capacity in skin integument was also observed in European seabass larvae after 2 days of UVB $\left(0.8 \mathrm{~W} \mathrm{~m}^{-2}\right)$ exposure. Ionocytes were less abundant, and a decrease in the fluorescent immunostaining of two important osmoeffectors, $\mathrm{Na}^{+} / \mathrm{K}^{+}$-ATPase and the $\mathrm{Na}^{+} / \mathrm{K}^{+} / 2 \mathrm{Cl}^{-}$ cotransporter, was observed in the UVB exposed larvae (Sucré et al. 2012). The gill filaments and lamellae in Indian major carp (Catla catla) were damaged by UVB radiation. Larvae exposed for 54 days $\left(1.45 \mathrm{~W} \mathrm{~m}^{-2}, 15 \mathrm{~min}\right.$ each day) showed damage in gill epithelium, and scanning electron microscopy revealed a decrease in the number of microridges. In addition, the pavement cells were severely affected (Sharma and Chakrabarti 2006). The same conditions of UVB radiation may also have had negative impacts on the digestive physiology and immune system of Indian major carp, contributing to poor growth and survival. After 55 days of exposure, the activity of the digestive enzymes amylase, trypsin and chymotrypsin decreased in carp larvae, suggesting an impairment of carbohydrate metabolism and protein digestion. Lower levels of the lysozyme, an important innate immune parameter, were observed in UVB treated fish, being an indicator of immune system suppression in carp larvae (Sharma et al. 2010). The tissue damage caused by UVB exposure in this species can be explained by the higher levels of glutamate oxaloacetate transaminase and glutamate pyruvate transaminase observed in UVB exposed larvae (Sharma et al. 2010). Further evidence of immune system suppression caused by UVB radiation during early development stages was suggested by Singh et al. (2013). They observed a decrease in leucocytes and in the myeloperoxidase activity in exposed larvae of roha labeo.

\section{Impairment of molecular and cellular processes}

At the molecular and cellular level, direct and indirect photochemical pathways characterize the toxic effects because of UVR exposure (Vincent and Neale 2000). Certain macromolecules, mainly nucleic acids and proteins, are directly targeted biologically by UVR due to the absorption of specific wavelengths by these molecules, followed by the dissipation of the absorbed energy under photochemical reactions (Sinha and Häder 2002; Setlow and Setlow 1962; Wilson et al. 1995). Photochemical transformation or degradation of these macromolecules can lead to impairment or even loss of their specific biological functions. Photooxidative breakdown of proteins and cross-linking of amino acids can occur due to the excess excitation energy that results from the absorption by specific aromatic amino acids including tyrosine, tryptophan, and phenylalanine of specific UV wavelengths (Gerhardt et al. 1999; Wilson and Greenberg 1993; Wilson et al. 1995).

Among the UVR absorbing macromolecules, nucleic acids are the most sensitive to UVR exposure (Buma et al. 2003; Vincent and Neale 2000). The wavelength of maximum absorbance of nucleic acids is around $260 \mathrm{~nm}$, but also extends into the UVB spectral region, and can result in the photo-destruction of nucleotides, essentially the pyrimidines, thymine, and cytosine, generating different photoproducts (Görner 1994; Setlow 1974). The degree and type of DNA damage depends on the intensity and the specific wavelength of the exposure. Three types of photoproducts can be generated as a result of UVR exposure: cyclobutane pyrimidine dimers (CPDs), pyrimidine [6-4] pyrimidone photoproduct (6-4 PP) and photohydrates (Görner 1994). Moreover, the DNA damage caused by these photoproducts can induce the impairment of essential cellular processes, such as blocking DNA replication and transcription that can result in severe deleterious consequences, including mutagenesis, apoptosis, and carcinogenesis (Hart and Setlow 1974; Mitchell et al. 1993, 2001; Setlow et al. 1989, 1993).

Pyrimidine dimers, CPDs (mainly the thymine TT dimers), are the predominant photoproducts generated as a result of UVB exposure (Buma et al. 2003; Thoma 1999) and CPDs have been described as a potential inhibitor of embryonic and larval development in fish (Lesser et al. 2001; Vehniäinen et al. 2012; Vetter et al. 1999). In blackfin icefish (Chaenocephalus aceratus) fertilized eggs, biological weighting functions (BWF) and exposure-response curves showed that CPDs formation is significantly correlated with the cumulative daily dose of UVB radiation. It was calculated that damage to DNA of approximately $35 \mathrm{CPD} / \mathrm{Mb}$ was induced in icefish eggs (unhatched, late-somitic 
stages) due to ozone layer depletion (Malloy et al. 1997). Likewise, due to the abundance, buoyancy and transparency of icefish eggs, the authors propose that this species could be a potential biological indicator of the DNA-damaging effects of UVB in zooplanktonic communities confined to Antarctic surface waters (Malloy et al. 1997). In another study, $10 \%$ of the estimated Atlantic cod embryo mortality was caused by an increased load of $10 \mathrm{CPD} / \mathrm{Mb}$ (megabase) to DNA after exposure over $1 \mathrm{~h}$ to $150 \mathrm{~kJ} \mathrm{~m}^{-2}$ of UVB. The CPDs loads were generally lower in eggs than in larvae, and only wavelengths shorter than $360 \mathrm{~nm}$ were shown to have a strong effect on CPDs formation. The eggs' characteristics, including the chorion (membrane) and the fluid-filled perivitelline space, can provide the embryos with some protection from UVB induced DNA damage (Browman et al. 2003).

This direct relationship between the number of generated pyrimidine dimers and the increase in mortality was also observed in fathead minnow (Pimephales promelas) embryos and rainbow trout (Oncorhynchus mykiss) larvae, (Applegate and Ley 1988; Mitchell et al. 2008). UVB induced DNA damage in the form of CPDs was also observed in different strains of Japanese medaka larvae exposed to different UVB conditions $\left(2.7-5.9 \mathrm{~mW} \mathrm{~m}^{-2}\right)$ and a positive correlation was observed between the UVB intensity and the generated CPDs number (Armstrong et al. 2002). Similar findings were reported for northern pike exposed for 2 days to UVB (0.24-1.7 $\mathrm{W} \mathrm{m}^{-2}, 3 \mathrm{~h} \mathrm{~d}^{-1}$ ), (Vehniäinen et al. 2012). The CPDs localization was investigated using immunohistochemistry in the northern pike tissues. At the highest UVB irradiances $\left(0.97-1.7 \mathrm{~W} \mathrm{~m}^{-2}\right.$ ), CPDs were found not only in the epidermal cells but also in the brain, eye and muscle. Such DNA damage in the eyes and brain in this species is associated with the severe behavioral disorders and mortality that were observed in this study (Vehniäinen et al. 2012). To the best of our knowledge, information on the occurrence of 6-4 PP photoproducts during early fish development is scarce. Although 6-4 PP induced lesions are less frequent under exposure to UVR, these photoproducts can have more damaging effects by blocking replication and transcription (Mitchell and Nairn 1989).

Several indirect photochemical mechanisms also mediate the damaged caused by UVR exposure; they generally involve the absorption of some photosensitizing agents, generating reactive oxygen species
(ROS), such as superoxide radicals $\left(\mathrm{O}_{2}^{--}\right)$, hydrogen peroxide $\left(\mathrm{H}_{2} \mathrm{O}_{2}\right)$, and hydroxyl radical $(\mathrm{OH})$, (Kieber et al. 2003). These highly energetic oxidative species can diffuse and react rapidly with several cellular components, resulting in damaged sites that can differ from the site of photoproduction (Vincent and Neale 2000). Cha et al. (2011) observed in zebrafish embryos a significant increase in intracellular ROS after exposure to $0.5 \mathrm{~kJ} \mathrm{~m}^{-2} \mathrm{UVB}$. The detection of ROS in the embryos was analyzed using the oxidationsensitive fluorescent probe dye, $2^{\prime}, 7^{\prime}$-dichlorofluorescein di-acetate (DCF-DA), (Cha et al. 2011). Another study in the same species revealed more ROS in 120 hpf larvae when the embryos were exposed to UVB, $0.25 \mathrm{~kJ} \mathrm{~m}^{-2}$ (Hurem et al. 2018). Despite the involvement of UVA in the mechanisms of repairing DNA damage, exposure to UVA in North African catfish (Clarias gariepinus) resulted in a significant increase in DNA damage, confirmed by the comet assay technique, (Mekkawy et al. 2010). As the levels of DNA damage were positively correlated with the lipid peroxidation results, the authors emphasized an oxidative nature of DNA damage in that study (Mekkawy et al. 2010). The DNA damage triggered by UVA is generally an indirect mechanism, and involves the formation of reactive chemical intermediates, including $\mathrm{O}_{2}^{-}$and $\mathrm{OH}$ radicals and their interaction with the DNA. Such interaction can result in the DNA strand breaks, DNA-protein cross-links, and alkali labile sites (Thoma 1999). In addition, lipid peroxidation (LPO) and consequent oxidative damage was observed in zebrafish larvae when the embryos were exposed to UVA doses $\geq 374 \mathrm{~kJ} \mathrm{~m}^{-2}$, and afterwards resulted in behavioral changes including a reduction in larval movement (e.g., changes in the resting heart rate, less time spent swimming), (Hurem et al. 2018).

Exposure to UVR during the early development stages can induce transcriptional changes. In zebrafish embryos, the expression of osteonectin (osn) increased after exposure to $4.9 \mathrm{~W} \mathrm{~m}^{-2}$ of UVB for $150 \mathrm{~min}$, and it was accompanied by an increase in mortality and developmental abnormalities (Nuñez et al. 2012). The increase in osn expression may be one of the plausible molecular mechanisms of UV radiation-induced phenotypic developmental abnormalities (Nuñez et al. 2012). In mammals, osteonectin has been described as a facilitator in the development of skin tumors in response to UVR exposure (Aycock et al. 2004). 
Moreover, the expression of $p 53$ was also upregulated in response to UVR (UVB and shorter UVA wavelength). This gene is generally associated with the DNA repair system, and low expression levels during embryogenesis are associated with normal development (Nuñez et al. 2012). Additionally, UVB radiation induces p53 activation in the brain, suggesting that neural molecular changes can be associated with behavioral changes observed in pike larvae (Vehniäinen et al. 2012). DNA damage and subsequent activation of p53 was observed in Atlantic cod embryos exposed to UVB. The activation of p53 is generally associated with DNA damage after exposure to UVB, which results in delays in cell division while DNA repair is taking place (Lesser et al. 2001). However, when the embryonic cells are unable to repair the DNA damage due to UVB exposure, the apoptosis pathway can be triggered. The activation of apoptotic pathways in response to UVR was reported in Japanese flounder (Paralichthys olivaceus) embryos, (Yabu et al. 2003). Using a caspase-3-like activity assay and terminal deoxynucleotidyl transferase-mediated dUTP nick end-labeling staining, the authors observed an induced extensive apoptosis in embryos after exposure to UVR $\left(0.2-1 \mathrm{~kJ} \mathrm{~m}^{-2}\right)$. Flounder embryos exposed to UVR revealed apoptotic cells distributed throughout the body, particularly in the head, spinal cord, yolk sac, heart and larval fin (Yabu et al. 2003).

An up-regulation in cellular defense (superoxide dismutase sod1, catalase cat 1 , heat shock protein 70 hsp70) and immune (interleukin-1 beta $i l-1 \beta$, tumor necrosis factor alpha $t n f \alpha$ ) related genes was observed in $96 \mathrm{hpf}$ zebrafish larvae after exposure to UVB $\left(0.11 \mathrm{~W} \mathrm{~m}^{-2}\right.$ ) over 4 days (Aksakal and Ciltas 2018). The authors suggest that the antioxidant defense response and the chaperoning mechanisms involved in larvae development were induced after UVB exposure. Furthermore, UVB seems to modulate the innate immune system in zebrafish larvae, as evidenced by the increase in gene expression of proinflammatory cytokines $i l-1 \beta$ and $t n f \alpha$ (Aksakal and Ciltas 2018). Similar results were observed by Banerjee and Leptin (2014) where the up-regulation of $i l$ $1 \beta$ was proportional to the increase in UVB dose. The authors suggested that such increased levels of this pro-inflammatory cytokine counteract the lethal effect of high doses of UV in zebrafish.
Juveniles and adults

Growth reduction, behavioral and metabolic changes

UVB radiation is known to affect fish growth and their body condition (Tables 3 and 4, see summary in Fig. 2). In Atlantic salmon (Salmo salar) juveniles, a reduction in growth and loss in body condition was observed after exposure in cages for 8 weeks to sunlight supplemented with UVB radiation (at depth of $1 \mathrm{~cm}-31.0 \mathrm{~kJ} \mathrm{~m}^{-2} \mathrm{~d}^{-1}$, at bottom of the cage$3.50 \mathrm{~kJ} \mathrm{~m}^{-2} \mathrm{~d}^{-1}$ ). The results were compared with fish kept under UVB depleted natural sunlight (at depth of $1 \mathrm{~cm}-0.45 \mathrm{~kJ} \mathrm{~m}^{-2} \mathrm{~d}^{-1}$, at bottom of the cage- $0.00 \mathrm{~kJ} \mathrm{~m}^{-2} \mathrm{~d}^{-1}$ ), (Jokinen et al. 2008). Subadult three-spined stickleback (Gasterosteus aculeatus) showed a similar reduction in growth and loss in body condition after exposure over 10 weeks to UV-enhanced conditions $\left(0.33 \mathrm{~W} \mathrm{~m}^{-2}\right.$, daily dose$6.48 \mathrm{~kJ} \mathrm{~m}^{-2}$ ), when compared with fish exposed to natural UVB conditions $\left(0.21 \mathrm{~W} \mathrm{~m}^{-2}\right.$, daily dose$3.89 \mathrm{~kJ} \mathrm{~m}^{-2}$ ), (Vitt et al. 2017). A potential reduction in the investment to the adaptive immunity due to a lower splenosomatic index was observed in the UVBenhanced treatment (Vitt et al. 2017). As suggested by the authors mentioned above, under these chronic stress conditions, fish possibly allocate energy for repairing UVB-induced DNA damage mechanisms (nucleotide excision repair) instead of using the energy for digestion (Jokinen et al. 2008; Vitt et al. 2017). Changes in feeding behavior, appetite reduction and catabolism stimulation in fish can be triggered by stress during UVB exposure (Arts et al. 2010; Holtby and Bothwell 2008; Vitt et al. 2017). Such suppression in the energy allocated for digestion was also suggested by the reduced growth observed in sea chub (Graus nigra) juveniles after short-term exposure (7 days) to a total UVB dose of $22.68 \mathrm{~kJ} \mathrm{~m}^{-2}$ (Pulgar et al. 2017).

The mechanisms underlying how fish perceive UVR and the changes in behavior that are triggered by UVR are poorly understood. Nevertheless, exposure to UVB generally results in an increase in oxygen consumption. This increase can be related to restless behavior and to an increase in swimming activity (Alemanni et al. 2003; García-Huidobro et al. 2017). Such an increase in oxygen consumption seems to be positively correlated with an increase in UVB doses in rainbow trout juveniles (Alemanni et al. 2003). 


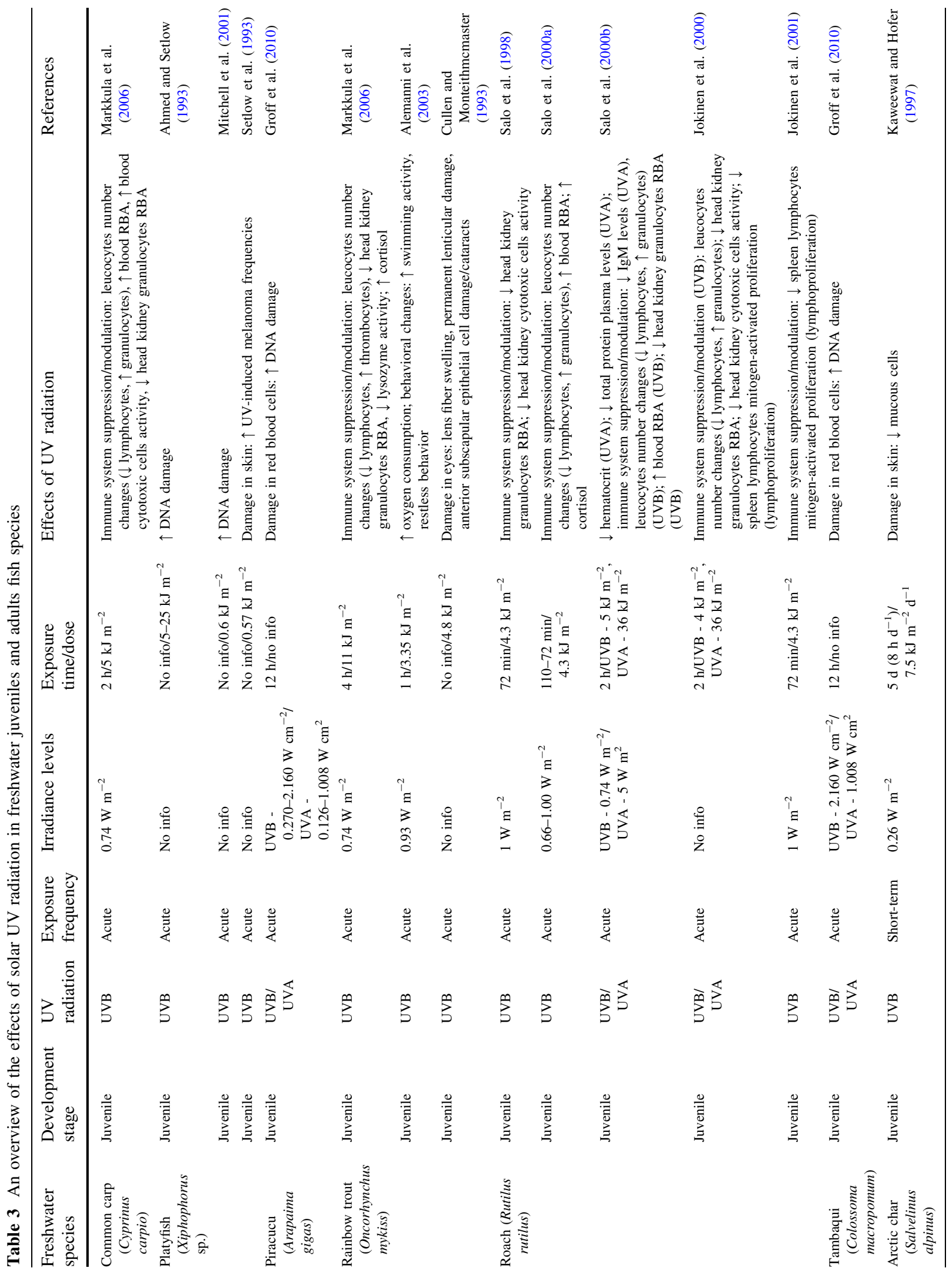




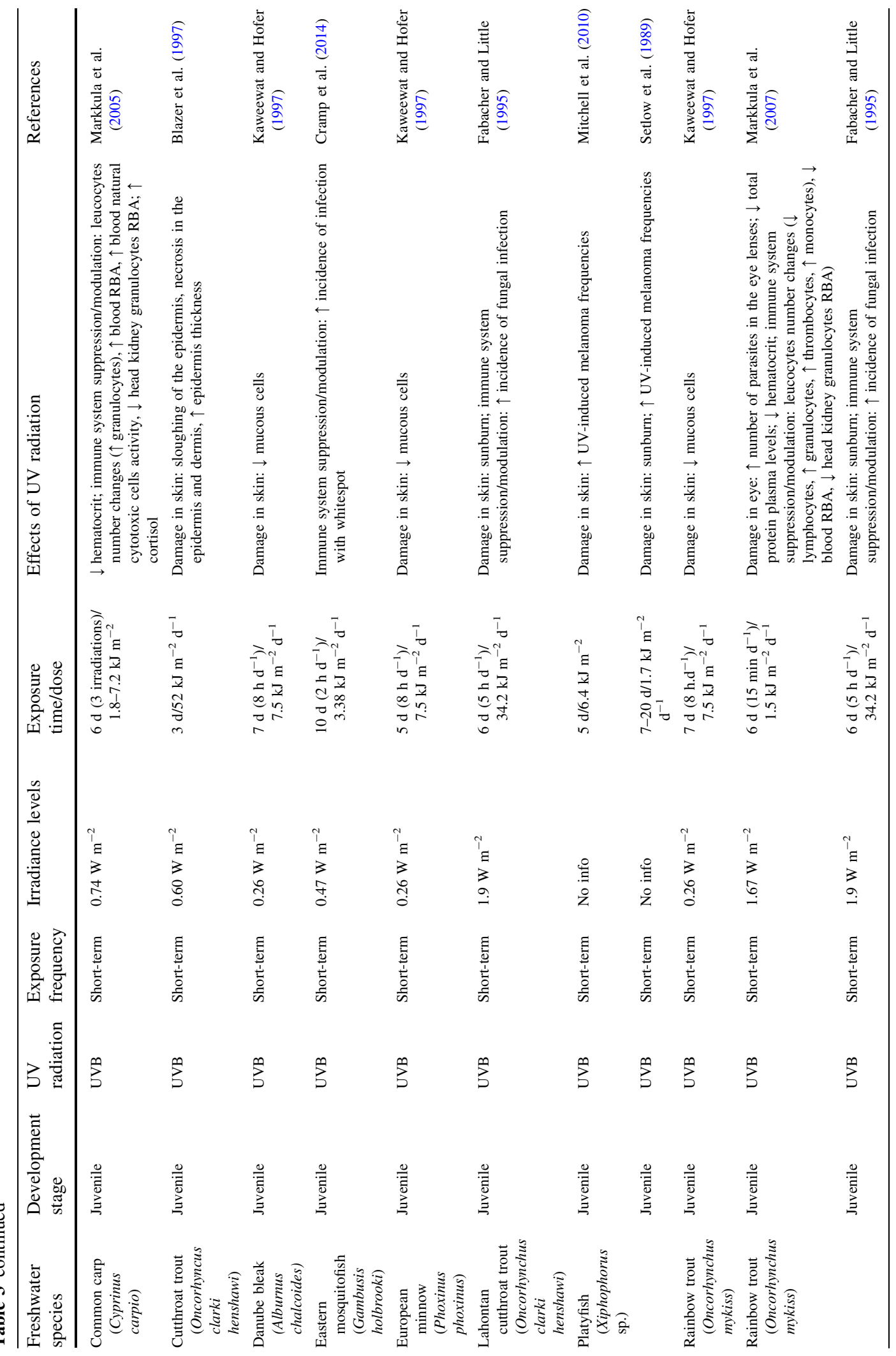




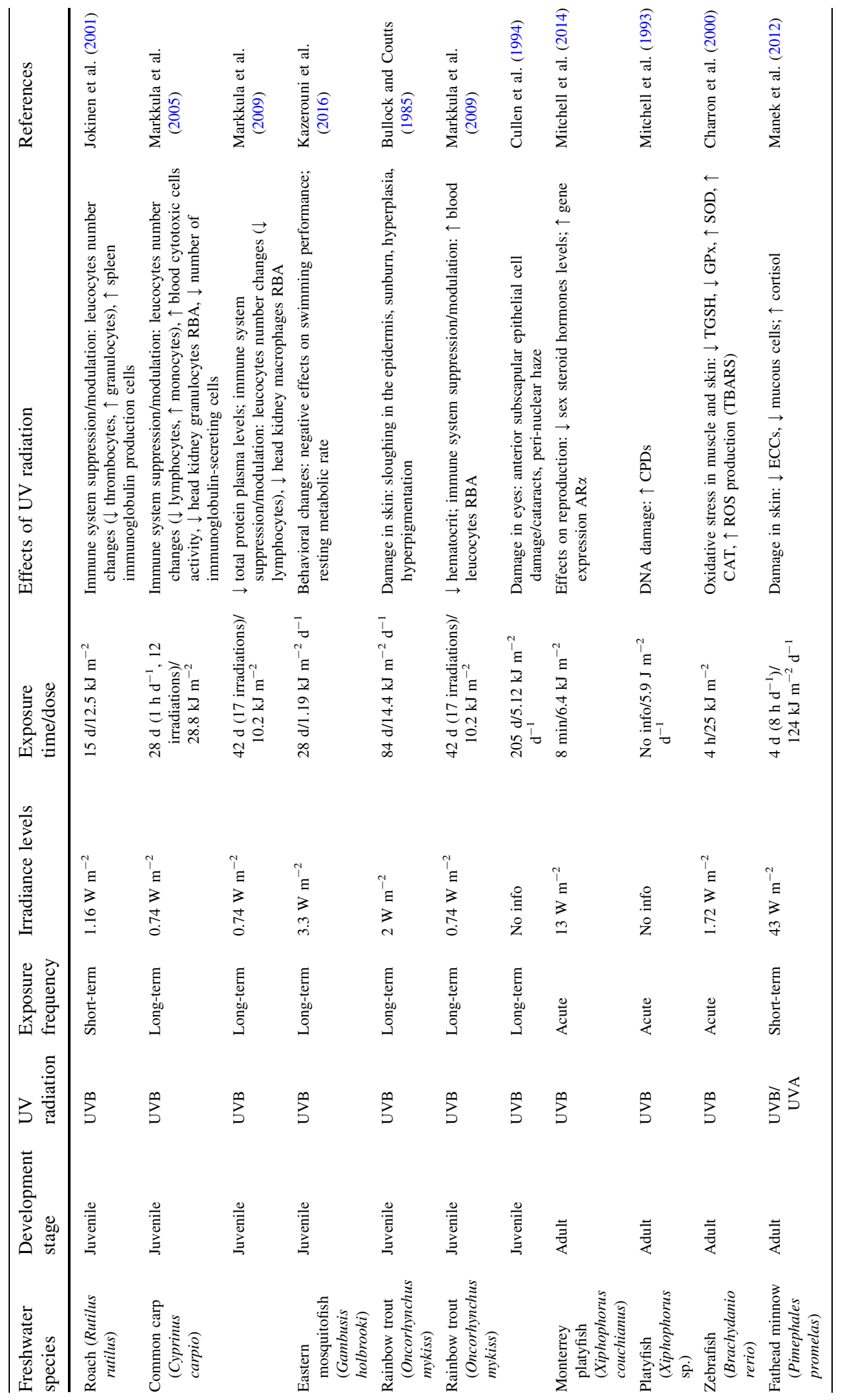




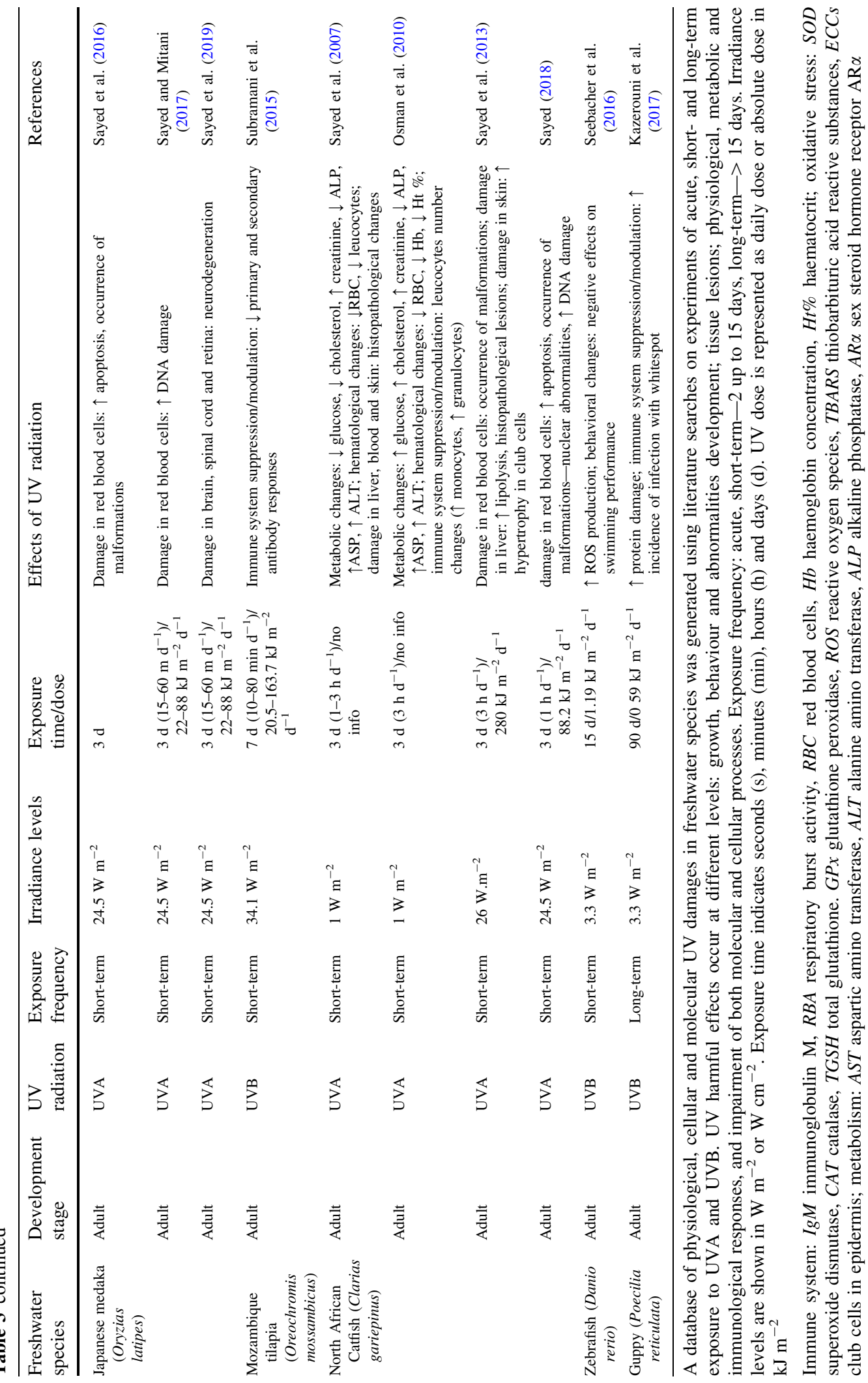


Nevertheless, zebrafish showed reduced swimming performance when exposed to UVB for two weeks $\left(3.3 \mathrm{~W} \mathrm{~m}^{-2}, 1.19 \mathrm{~kJ} \mathrm{~m}^{-2} \mathrm{~d}^{-1}\right)$. This reduction in muscular activity can be part of a mechanism to minimize intrinsic reactive oxygen species (ROS) production after exposure to UVB (Seebacher et al. 2016). The predatory performance of the reef fish Patagonothen cornucla, a species inhabiting the intertidal areas of the Patagonian coast, was affected after UVB exposure (Valinas and Helbling 2016). The prey capture time increased in the juveniles exposed to UVB for 9 days (Valinas and Helbling 2016). Longterm exposure to UVA radiation (30 days, daily dose of $55.6 \mathrm{~kJ} \mathrm{~m}^{-2}$ ) in three-spined stickleback adults affects reproductive performance by decreasing sperm velocity and by inducing changes in the breeding coloration (Rick et al. 2014).

\section{Tissue lesions and physiological changes}

Exposure to UVR results in severe lesions in organs and tissues, including those that are directly exposed such as the skin and eyes (Tables 3 and 4, see summary in Fig. 2). The skin constitutes a primary barrier and acts as the interface between the fish and its external environment (Esteban 2012). Unlike humans, the inexistence of a keratinized outer layer in fish skin results in higher vulnerability to UVR exposure. In the Lahontan cutthroat trout (Oncorhynchus clarki henshawi) and rainbow trout, signals of sunburn appeared after 3 days (UVB daily dose, $34.2 \mathrm{~kJ} \mathrm{~m}^{-2}$ ) of exposure. The darkening of the skin may have resulted from melanosome dispersion, a characteristic symptom observed after sunburn. The largest area of sunburn occurred just after the head and relatively close to the dorsal fin. After 6 days of exposure, both species had a significant fungal infection. No sunburn or fungal infection was observed in the apache trout (Oncorhynchus apache) or razorback suckers (Xyrauchen texanus) under the same UVB conditions (Fabacher and Little 1995). Appearance of sunburn cells, epidermis necrosis and edema, disruption between the epidermis and the basement membrane, changes in the skin thickness, and hyperplasia of superficial mucous cells are some of the microscopic changes observed in the cutthroat trout skin after UVB exposure. Below the stratum compactum, the melanocyte layer was thickened and more disorganized in some areas in UVB exposed fish (Blazer et al. 1997).
Other evidence of the harmful effects of UVB in the skin are changes observed in the metabolically active mucous tissue. The mucous layer corresponds to the outer extrinsic barrier representing the first line of defense against pathogenic microorganisms in the surrounding water (Esteban and Cerezuela 2015; Gomez et al. 2013). The number of mucous producing cells, also called goblet cells, decreased significantly in the dorsal skin of juvenile Arctic char (Salvelinus alpinus), European minnow (Phoxinus phoxinus), Danube bleak (Alburnus chalcoides) and rainbow trout after 5-7 days of UVB exposure $\left(7.5 \mathrm{~kJ} \mathrm{~m}^{-2}\right.$ $\left.\mathrm{d}^{-1}\right)$. No effects of UVA were observed in the number of mucous producing cells. A decrease in the number of mucous producing cells can affect the innate immune response because of less mucous production (Kaweewat and Hofer 1997). Similar findings were observed in adult fathead minnow after acute exposure to UVA/UVB for $8 \mathrm{~h}$ (irradiance levels $43 \mathrm{~W} \mathrm{~m}^{-2}$ ). In addition, a reduction of $50 \%$ in the number of epidermal club cells (alarm cells) was observed in the UVR treated fish, but without significant changes in the epidermis thickness (Manek et al. 2012). Both mucous and alarm cells in the dorsal skin of North African catfish were severely damaged after 3 days exposure to UVA (total dose- $10.8 \mathrm{~kJ} \mathrm{~m}^{-2}$ ). In the ventral skin, an increase in the epidermis thickness as well as the appearance of pyknotic cells and signs inflammation were visible in the UVA exposed fish (Sayed et al. 2007).

During the last 3 decades, several platyfish interspecies genetic hybrid models were developed to investigate the role of UVR on the induction of cutaneous malignant melanoma (Ahmed and Setlow 1993; Mitchell et al. 1993, 2001; Setlow et al. 1989, 1993). A pioneer study by Setlow et al. (1989) demonstrated that UVR has a potential role in the etiology of melanoma. The authors observed that backcross hybrids irradiated with UVB showed a higher frequency of induced melanoma compared to the spontaneous melanoma levels. Later, a study performed by Mitchell et al. (2010) on the UVR action spectrum for melanoma induction, using the Xiphophorus couchianus model, showed that UVB could induce melanoma in this animal model; however, UVA did not. These authors also suggested that the direct DNA damage (formation of CPDs and 6-4 $\mathrm{PP}$ ) associated with UVB could play a major role in the initiation of melanomas. Moreover, the efficient 
capacity of fish to repair UVB-induced DNA damage by the photoenzymatic repair system seems to decrease the occurrence of melanoma in the Xiphophorus melanoma model (Mitchell et al. 1993, 2001).

Corneal epithelium/stroma damage and persistent cataractous changes in the anterior part of the crystalline lens occurred in the eyes of rainbow trout exposed to UVB $0.75-15 \mathrm{~kJ} \mathrm{~m}^{-2}$ (Cullen and Monteithmcmaster 1993; Doughty et al. 1997). Furthermore, cataractous changes in rainbow trout under long-term exposure to UVB (205 days, dose $5.12 \mathrm{~kJ} \mathrm{~m}^{-2} \mathrm{~d}^{-1}$ ) include 'doughnut' opacities, discrete anterior subcapsular and peri-nuclear haze in the fish eye lenses, supporting the cataractogenic role of UVR (Cullen et al. 1994). In zebrafish, UVB exposure resulted in a reduction in corneal thickness but the lens capsule diameter and fiber thickness were not affected (Marlow 2010). UVB-exposure over 6 days resulted in an increase of Diplostomum spathaceum metacercariae parasites present in the rainbow trout eye lenses compared with the control group. This increase in the number of parasites was accompanied by a thinner mucus layer in the dorsal skin (Markkula et al. 2007). An ultrastructural study demonstrated that acute exposure to UVB $1.4 \mathrm{~W} \mathrm{~m}^{-2}\left(10.08 \mathrm{~kJ} \mathrm{~m}^{-2}\right)$ for $2 \mathrm{~h}$ changed the outer surfaces of the eyes and skin in ayu (Plecoglossus altivelis). Damage to the specialized microridges, which are generally related to stress adaptation, was observed in the skin and eyes of UVB exposed fish (Sharma et al. 2005). UVR-induced changes and damage have also been noted in organs that were not directly exposed to radiation, such as, in the red blood cells and liver (Table 3). In Japanese medaka, UVA exposure for 3 days promoted apoptosis and induced several morphological malformations in red blood cells, such as acanthocytes, hemolyzed cells, sickle cells, swollen cells and cell membrane lysis. Moreover, several nuclear abnormalities including deformed nuclei, eccentric nuclei, nuclear budding and bilobed nuclei were identified in the UVA exposed fish (Sayed 2018; Sayed et al. 2013, 2016). Hepatic tissue was also damaged by UVA in Japanese medaka. Dilated thick-walled blood vessels in association with inflammatory lymphocytic infiltration, diffused hepatic pigments, irregular shape of some nuclei and loss of cellular integrity, fatty degeneration (lipidosis) associated with lipid accumulation and cytoplasmic vacuolation were evident in UVA-treated fish (Sayed et al. 2007, 2013).

Several physiological responses to UVR exposure have been reported in juvenile and adult fish (Tables 3 and 4, see summary in Fig. 2). Plasma cortisol levels increased after exposure to UVB radiation in rainbow trout, roach (Rutilus rutilus) and fathead minnow. Such increases in cortisol levels, a primary endocrine response of fish to stressful conditions, generally induce physiological, immunological and metabolic changes, thus affecting fish growth (Manek et al. 2012; Markkula et al. 2006; Salo et al. 2000a, b). Moreover, the role of UVB as an endocrine disruptor was investigated in the platyfish Xiphophorus coachianus melanoma model. The exposure to a sublethal dose of UVB for $8 \mathrm{~min}$ in adult males resulted in a remarkable increase in the circulating levels of both sex steroid hormones and gene expression levels in its associated hormone receptor, $\mathrm{AR} \alpha$. The authors suggested that this photoendocrine response could be a key factor in male tumorigenesis due to its potential involvement in the initiation of UV-induced melanoma (Mitchell et al. 2014). Short- and long-term UVB exposure decreases both hematocrit and plasma total protein levels in Atlantic salmon, roach, rainbow trout and common carp (Cyprinus carpio). A decrease in both indicators revealed poor nutritional and health status in the fish exposed to UVB (Jokinen et al. 2008, 2011; Markkula et al. 2007; Salo et al. 2000b). Nevertheless, the total protein levels in the plasma increased in North African catfish after 3 days of UVA exposure $\left(3 \mathrm{~h} \mathrm{~d}^{-1}\right)$. UVAtreated fish revealed changes in several biochemical, hematological and metabolic parameters. For example, the levels of creatinine, alanine amino transferase and aspartic amino transferase increased after UVA treatment, but most of the parameters, such as the levels of glucose, cholesterol, alkaline phosphatase, hematocrit, hemoglobin, red blood cells, and platelets, decreased in UVA exposed catfish, suggesting that UVA can also induce a metabolic and physiologic disturbance in adult fish (Sayed et al. 2007).

\section{Immune system modulation}

The reported detrimental effects of UVR in innate and acquired immune systems in fish showed variations between species and the duration of exposure. Impacts of UVA and UVB include negative effects on both cellular and humoral components of the fish immune 


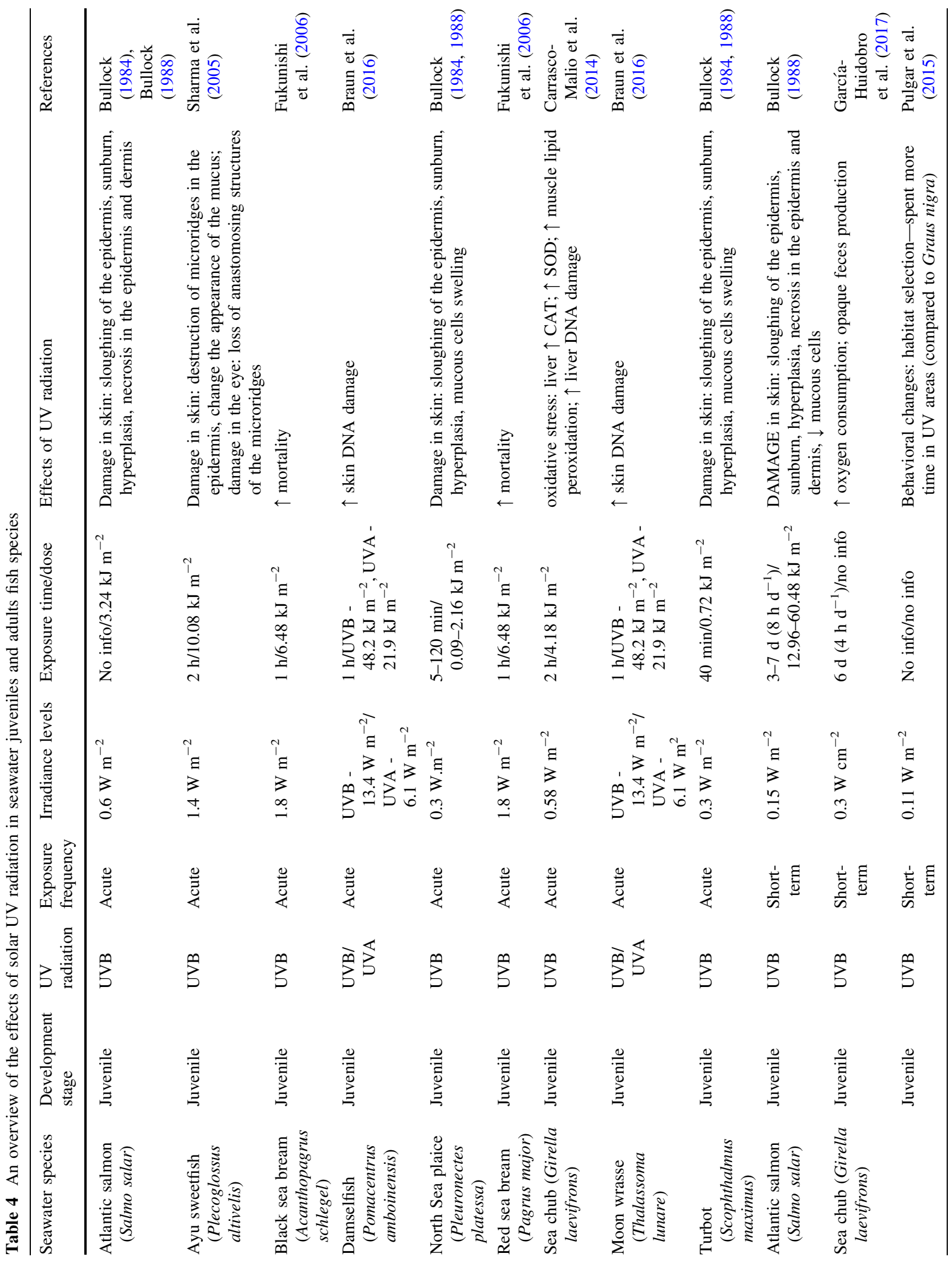




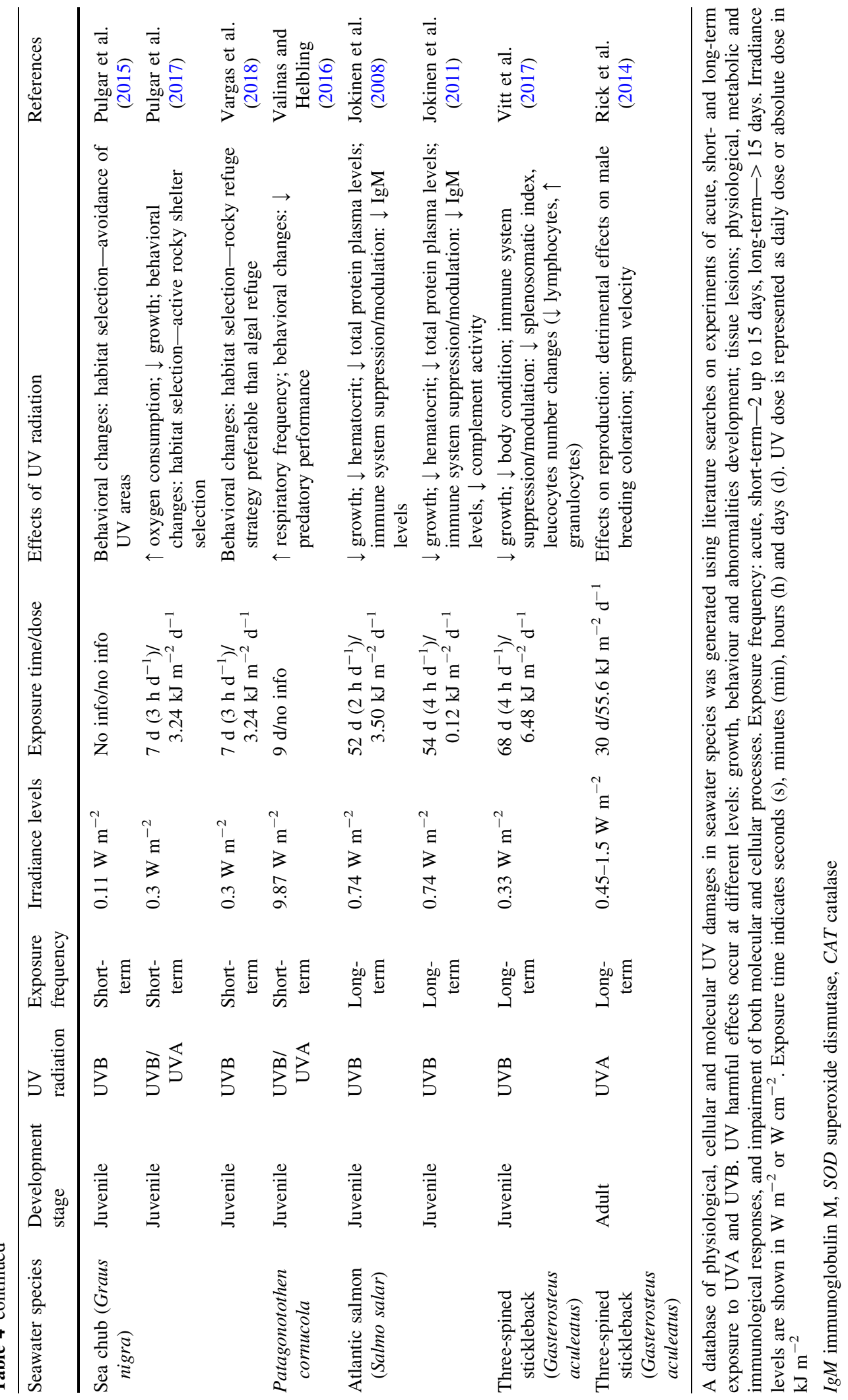




\title{
(A) Growth reduction, behavioral and metabolic changes
}

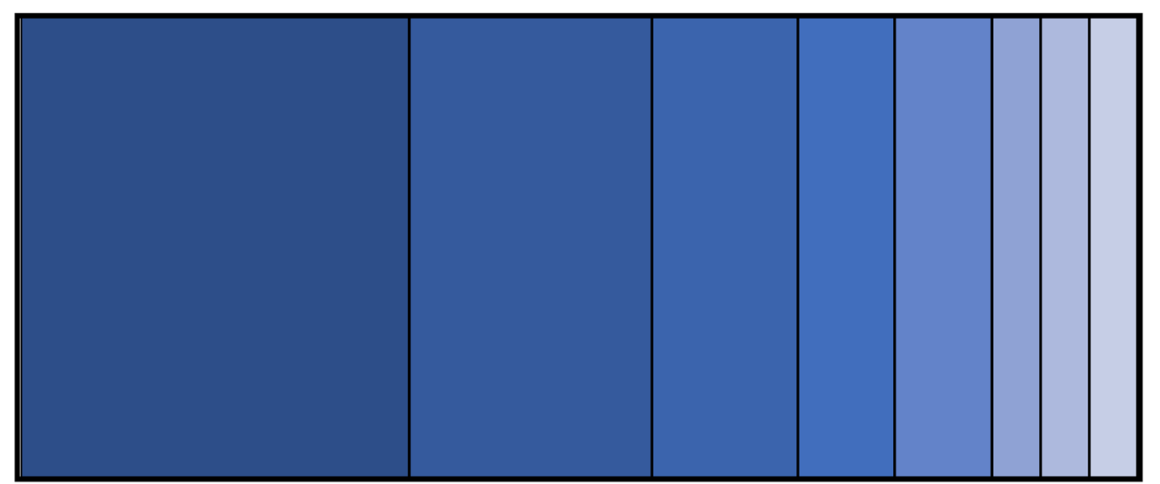

$\square$ behavioral changes

$\square \downarrow$ growth/body condition

$\square \uparrow$ oxygen consumption

$\square \uparrow$ mortality

$\square$ effects on reproduction

$\square \uparrow$ respiratory frequency

$\square$ metabolic changes

$\square$ opaque feces production

(B) Physiological changes and impairment of molecular and cellular processes

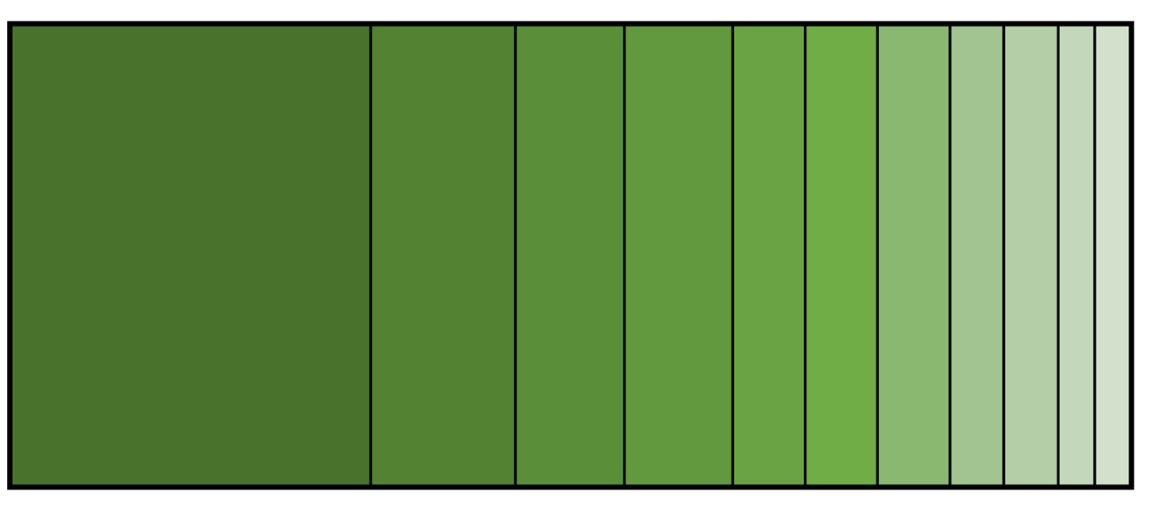

$\square$ skin damage

$\square \uparrow$ DNA damage

$\square \downarrow$ hematocrit

$\square \downarrow$ total protein plasma

$\square$ eye damage

$\square$ red blood cells damage

$\square \uparrow$ cortisol

口liver damage

$\square$ oxidartive stress

$\square$ protein/lipid damage

$\square$ apoptosis

\section{(C) Immune system suppression/modulation}

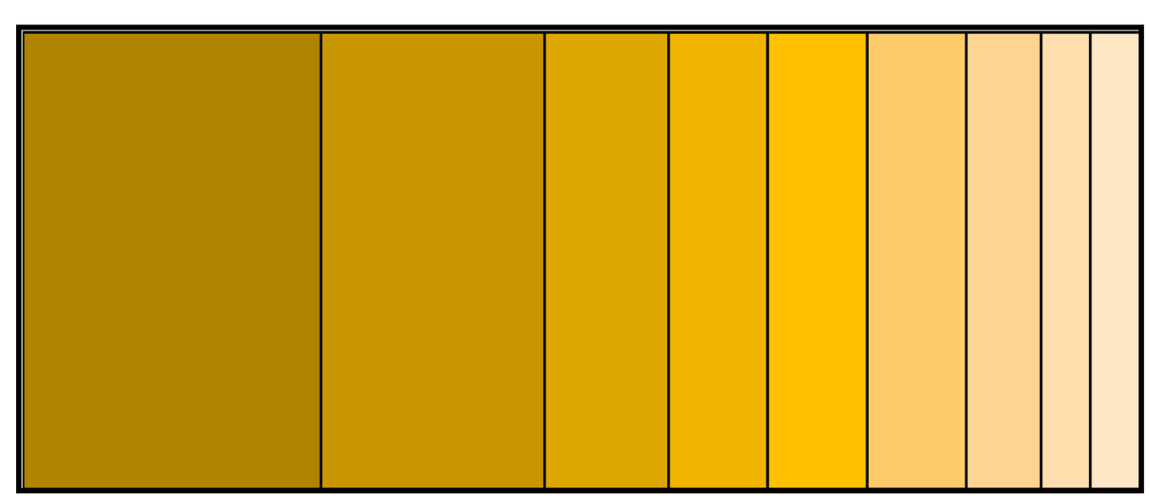

\author{
$\square$ leucocytes changes \\ $\square \downarrow$ head kidney RBA \\ $\square \uparrow \downarrow$ blood RBA \\ $\square \uparrow \downarrow$ immunoglobulins \\ $\square \uparrow$ incidence of infection \\ $\square$ others \\ $\square \uparrow$ blood NCC activity \\ $\square \downarrow$ head kidney NCC activity \\ $\square \downarrow$ lympocytes mitogen-activated
proliferation
}

Fig. 2 Summary of current knowledge regarding the adverse effects of UVR in juveniles and adult fish. a Effects on growth and changes in behavior and metabolism; $\mathbf{b}$ changes in physiology status and impairment of molecular and cellular processes; $\mathbf{c}$ changes in the immune system. The color intensity represents the number of studies reporting each detrimental effect, in which the stronger the color/bar size the higher the number of references for each detrimental effect. $R B A$ respiratory burst activity, $N C C$ non-specific cytotoxic cells 
system (Tables 3 and 4, see summary in Fig. 2). One of the most common negative effects of UV exposure is the change in the proportion of the different leucocytes in peripheral blood. In Rutilus rutilus, which generally inhabits lakes with low UVR, exposure to $4.3 \mathrm{~kJ} \mathrm{~m}^{-2} \mathrm{UVB}$ resulted in a significant increase in the percentage of granulocytes (control4-6\%, UVB exposed fish-35-37\%) and a significant decrease in the percentage of lymphocytes (control$56-60 \%$, UVB exposed fish-30-33\%) on day 1 of post-irradiation. These changes were not observed under UVA exposure for the same species. However, on day 14 after the exposure, the percentage of these leucocytes returned to similar levels to those observed in the control. No significant changes were observed in the percentage of monocytes or thrombocytes (Jokinen et al. 2000; Salo et al. 2000a, b). Under the same UVB dose, similar results were obtained in the common carp but not in the rainbow trout. The increase in the UVB dose $\left(11 \mathrm{~kJ} \mathrm{~m}^{-2}\right)$ in the rainbow trout resulted in a decrease in the lymphocytes percentage, but the granulocytes percentage remained unchanged. The number of thrombocytes increased $20 \%$ in the UVB exposed trout. In the common carp, these changes were dependent on the UVB dose (Markkula et al. 2006). The high levels of cortisol observed in the UVB exposed fish suggest that the occurrence of lymphopenia/granulocytosis in blood can be a stress response indicator to UVB exposure (Jokinen et al. 2000; Markkula et al. 2006; Salo et al. 2000a). In addition, repeated exposure (short- and long-term) to UVB also induced peripheral blood lymphopenia and granulocytosis. UVB exposure during six consecutive days (total dose $9 \mathrm{~kJ} \mathrm{~m}^{-2}$ ) improved the immune function of uninfected rainbow trout by increasing the number of circulating granulocytes in the blood (Markkula et al. 2007). Long-term exposure to UVB (28 days, total dose $28.8 \mathrm{~kJ} \mathrm{~m}^{-2}$ ) decreased the proportion of lymphocytes in the blood of common carp. Fish, showing lesions and infection in the dorsal skin during the third week of exposure, also presented an increase in the proportion of granulocytes and monocytes (Markkula et al. 2005). These results suggested that lymphocytes are sensitive to UVB radiation, and the increase of granulocyte-to-lymphocyte ratio in the UVB exposed fish can result in a higher contribution of the innate immune system compared to the adaptive immune system (Markkula et al. 2005; Vitt et al. 2017).
Production of ROS during phagocytosis, also known as respiratory burst activity (RBA), is essential for the effective destruction of pathogens (Uribe et al. 2011). This cellular component of the innate immune system is generally suppressed in the head kidney phagocytes after UVB exposure. In the roach, RBA of both macrophages and granulocytes decreased during the first two days after the UVB exposure (4-5 $\mathrm{kJ} \mathrm{m}^{-2}$ ), but the capacity of both leucocyte types to produce ROS was restored on day 7 post irradiation (Jokinen et al. 2000; Salo et al. 1998, 2000b). Similar findings in the common carp $\left(0.5-5 \mathrm{~kJ} \mathrm{~m}^{-2}\right)$ and rainbow trout $\left(10 \mathrm{~kJ} \mathrm{~m}^{-2}\right)$ granulocytes were described on day 1 after irradiation (Markkula et al. 2006). In the common carp, granulocytes RBA was significantly decreased in fish irradiated with $2.4 \mathrm{~kJ} \mathrm{~m}^{-2} \mathrm{~d}^{-1} \mathrm{UVB}$ for 1 week, whereas long-term exposure to UVB radiation decreased in fish irradiated with both 1.2 and $2.4 \mathrm{~kJ} \mathrm{~m}^{-2} \mathrm{~d}^{-1}$ UVB doses (Markkula et al. 2005). In contrast, leucocytes respiratory burst activity in peripheral blood generally increased in fish after UVB exposure. This probably occurred because of the granulocytosis observed in peripheral blood (Markkula et al. 2006; Salo et al. 2000a, b). In rainbow trout, repeated UVB exposure can increase or decrease the peripheral blood granulocytes RBA (Markkula et al. 2007, 2009). Another important cellular component of the innate immune system affected by UV exposure is the activity of non-specific cytotoxic cells, which generally shows the same pattern as RBA in peripheral blood and head kidney (Jokinen et al. 2000; Markkula et al. 2005, 2006; Salo et al. 1998). NCC in teleosts are the equivalent of the mammalian natural killer (NK) cells, being part of the natural defense against parasites, virus or even neoplastic diseases (Uribe et al. 2011); therefore, this protective mechanism can be affected by exposure to UVR.

Humoral components of the immune system of fish can also be suppressed by the exposure to UVR. In rainbow trout, four hours of exposure to UVB $\left(10 \mathrm{~kJ} \mathrm{~m}^{-2}\right)$ resulted in a significant decrease in lysozyme, which provides an essential defense against Gram-positive bacteria and activates both phagocytes and complements activity (Markkula et al. 2006; Saurabh and Sahoo 2008). Long-term exposure to UVB (54 days, dose at the bottom of the cage$0.12 \mathrm{~kJ} \mathrm{~m}^{-2} \mathrm{~d}^{-1}$ ) in Atlantic salmon decreased both complement bacteriolytic activity and 
immunoglobulin M (IgM) levels in the plasma (Jokinen et al. 2008, 2011). Salo et al. (2000a) demonstrated that UVA could also be a modulator of the immune systems in roach, by decreasing the plasma immunoglobulin levels. However, short-term exposure to UVB had no clear negative effects on the roach plasma immunoglobulin levels (Jokinen et al. 2001). Plasma IgM concentration decreased significantly in common carp juveniles exposed to the highest dose of UVB $\left(2.4 \mathrm{~kJ} \mathrm{~m}^{-2}\right.$, total dose $\left.28.8 \mathrm{~kJ} \mathrm{~m}^{-2}\right)$ after 4 weeks but not with other doses. Fish showing skin lesions and fungal infections also revealed significantly lower IgM levels compared to healthy fish (Markkula et al. 2005). This decrease in the IgM levels may be an indicator of the impairment in lymphocytes function due to UVB exposure (Jokinen et al. 2008, 2011). In addition, IgM levels may be indicative of the overall function of the acquired immune system, as the synthesis of IgM requires the activity of several cell populations, such as T-/B-lymphocytes and cytokines (Jokinen et al. 2008). The potential role of UVB to modulate the functioning of lymphocytes, and subsequently compromise the immune status of the fish, was also demonstrated through the suppression of the spleen lymphoproliferative (lymphocytes mitogen-activated proliferation) responses after exposure of $R$. rutilus to moderate UVB levels (Jokinen et al. 2000). In fact, the immune system modulation/suppression that resulted from the exposure to UVB can subsequently decrease the resistance of the fish to diseases. A high incidence of fungal infection on the skin of rainbow trout and lahontan cutthroat trout was observed after 6 days of exposure to UVB (1.9 $\mathrm{W} \mathrm{m}^{-2}$, ambient mid-latitude summer irradiance (Fabacher and Little 1995). Moreover, long-term UVB exposure in guppy (Poecilia reticulate) increased the fungal infection rates by white spot in their offspring, suggesting that UVB has an immunosuppressive effect across generations (Kazerouni et al. 2017). The negative effects of UVB on disease resistance were observed in rainbow trout, where the juveniles exposed to UVB showed a suppression in the resistance against trematode parasites (Diplostomum spathaceum) and bacteria (Yersinia ruckeri), (Markkula et al. 2007).
Impairment of molecular and cellular processes

DNA damage in the form of CPDs increased significantly on the skin of moon wrasse (Thalassoma lunare) after UVR treatment (1 h, UVA$21.9 \mathrm{~kJ} \mathrm{~m}^{-2}$, UVB- $48.2 \mathrm{~kJ} \mathrm{~m}^{-2}$ ). The level of DNA damage in the juveniles' wrasse skin was negatively correlated with the integrated mucus absorbance, represented by the amount of mycosporine-like amino acids (MAAs) present in the external skin mucus (Braun et al. 2016). UVR-induced DNA damage and its repair in the skin of platyfish species were described for the first time by Ahmed and Setlow (1993). Induced CPDs are up to 10 times more frequent than (6-4) PPs, and the efficiency of photoproduct generation seems to be tissue dependent in platyfish species. CPDs and (6-4) PPs can be efficiently repaired by dark- and light-dependent repair processes, being highly diverse in the Xiphophorus genus. This nucleotide excision repair showed high efficiency for the (6-4) PPs compared with the CPDs in most platyfish species (Mitchell et al. 1993, 2001). The authors concluded that differences in vulnerability of the several platyfish species/hybrids to the damaging effects of UVB to DNA could be a result of differences in the skin structure (e.g. morphology and composition of scales) and pigmentation. For example, in the absence of scales, the photoproducts generation was similar between skin and fins (Mitchell et al. 2001). DNA damage was also observed in the liver of $G$. laevifrons after 3-5 h of exposure to UVB (CarrascoMalio et al. 2014). UVA-induced DNA damage and repair in erythrocytes was investigated in Japanese medaka and North African catfish. Exposure of adult medaka during 3 days to UVA radiation resulted in high frequencies of $\gamma-\mathrm{H} 2 \mathrm{AX}$ foci (marker for DSBs) and tail moment score (neutral comet assay) immediately after exposure, and then decreased within $24 \mathrm{~h}$ (Sayed and Mitani 2017). A replication-independent formation of UVA-induced double-strand breaks through the generation of ROS and oxidative damage was suggested by the authors. In North African catfish, DNA damage and repair was a function of UVA dose and recovery after exposure. Comet assay results demonstrated that fish exposed to UVA had a significant increase in DNA damage compared with the controls (Sayed 2018). Based on the morphological changes, DNA damage and apoptosis results, the data 
suggest that Japanese medaka might be more sensitive to UVA exposure than the North African catfish.

The effects of UVR on oxidative stress have been reported in some fish species (Carrasco-Malio et al. 2014; Kazerouni et al. 2017). In adult zebrafish, changes in muscle and skin antioxidant status were observed after ambient UVB (4h, $1.72 \mathrm{~W} \mathrm{~m}^{-2}$ ). Total glutathione concentration and glutathione peroxidase activity decreased after 6 and $12 \mathrm{~h}$ of exposure. In contrast, superoxide dismutase and catalase activity peaked at 6 and $12 \mathrm{~h}$, respectively. In addition, lipid peroxidation was revealed by the increase in ROS in UVB-treated fish compared to the control fish. These results showed significant free radical-mediated lipid membrane damage by an increase in cytosolic hydrogen peroxide $\left(\mathrm{H}_{2} \mathrm{O}_{2}\right)$ and superoxide anion radicals $\left(\mathrm{O}_{2}{ }^{-}\right)$due to UVB exposure (Charron et al. 2000). An increase in the ROS-induced damage to proteins and membranes was also observed in adult zebrafish when exposed to UVB (daily dose $1.19 \mathrm{~kJ} \mathrm{~m}^{-2}$ ) during 15 days (Seebacher et al. 2016). These authors suggested that in the presence of UVB, fish could minimize the ROS production by reducing their swimming activity. In Girella laevifrons, differences in the antioxidant capacity were observed between liver and muscle. Catalase activity in the liver increased with the duration of UVB exposure $\left(0.58 \mathrm{~W} \mathrm{~m}^{-2}\right)$, but the superoxide dismutase activity peaked at $2 \mathrm{~h}$, followed by a decrease down to basal levels after $5 \mathrm{~h}$ of radiation. In the muscle, lipid peroxidation increased during $5 \mathrm{~h}$ of exposure to UVB (Carrasco-Malio et al. 2014).

\section{Photoprotective mechanisms}

Fish have developed different protective strategies to cope with the harmful effects of UVR exposure. These include: (1) behavioral changes to avoid UVB exposure; (2) the presence of physical barriers such as scales; (3) acquisition of UV-absorbing compounds; (4) elimination of toxic compounds resulting from the exposure to UVR; and/or (5) UV-induced damage repair mechanisms in proteins and DNA (Dahms and Lee 2010; Zagarese and Williamson 2001; Zamzow 2003, 2004, 2007). The changes in behavior to avoid UVR exposure and photoprotective mechanisms by UV-absorbing compounds are very important components in overall UVR protection (Dahms and Lee
2010). Avoidance of UVR exposure has been reported in several fish species. For example, coho salmon (Oncorhynchus kisutch) juveniles reared in outdoor flumes can perceive UVR and avoid overexposure by exhibiting a shade-seeking behavior. Agonistic interactions between individuals and natural feeding behavior were suppressed in the fish exposed to UVR (Holtby and Bothwell 2008). During a UVR avoidance experiment, black seabream (but not red seabream) showed the capacity to avoid the highest UVB levels (20 min of exposure to $1.1 \mathrm{~W} \mathrm{~m}^{-2}$ ) by hiding in the half of the tank that was covered with UV-blocking film. In fact, black seabream during their early life cycle stages generally live in shallower water with high UVB radiation levels (Fukunishi et al. 2006). Bluegill sunfish locate their nests in higher depths characterized by high UVR attenuation and in areas protected by overhanging trees or other structures, therefore increasing larvae survival success (Olson et al. 2006, 2008). One of the strategies of both intertidal fish species, Girella laevifrons and Patagonotothen cornucola to avoid UVR is living under rocks and/or areas abundant in algae (CarrascoMalio et al. 2014; Pulgar et al. 2015, 2017; Valinas and Helbling 2016).

UV-absorbing compounds (UVACs) play a protective role during UVR exposure in aquatic organisms and include carotenoids, mycosporins, melanin, scytonemin and the well-described mycosporine-like amino acids (MAAs). UVACs are common UVsunscreens that are synthesized by photosynthetic organisms and can be acquired by animals through their diet (Carefoot et al. 1998, 2000; Mason et al. 1998; Riemer et al. 2007; Zamzow 2004). MAAs are small photostable water-soluble compounds that can absorb UVB and UVA wavelengths (between 309 and $360 \mathrm{~nm}$ ). Besides their role in UV absorbance, these intracellular compounds can also be responsible for ROS scavenging (Oren and Gunde-Cimerman 2007). During early development, MAAs including gadusol were detected in eggs and larvae of several marine fish species (Lesser et al. 2001; Plack et al. 1981; Zagarese and Williamson 2001). Several MAAs were identified in the eye tissue of 52 reef fish species, including palythene $(\lambda \max -360 \mathrm{~nm})$, palythinol $(\lambda \max -$ $332 \mathrm{~nm})$, asterina-330 ( $\lambda \max -330 \mathrm{~nm})$ and palythine $(\lambda$ max $-320 \mathrm{~nm}$ ), (Dunlap et al. 1989). Most studies found that UVACs including MAAs in fish were found in the epidermal mucus. Fabacher and 
Little (1995) identified a UVB-absorbing compound in skin extracts of razorback suckers (Xyrauchen texanus) and apache trout (Oncorhynchus apache). This compound was more abundant in these two species when compared to the amount observed in rainbow trout and Lahontan cutthroat trout. These last two species showed high signals of fungal infection and skin sunburn after exposure to UVR (Fabacher and Little 1995). UVA and UVB absorbing compounds were detected in the epidermal mucous of more than 120 tropical reef fish species. For example, in the Hawaiian saddle wrasse (Thalassoma duperrey), UVR exposure induced changes in the absorbance of its mucous (Zamzow and Losey 2002). The type of diet and UVR exposure affected the UV-absorbing compound content in the mucous. Furthermore, differences in UV absorbance by $T$. duperrey epidermal mucous were found between male and females. Mucous in females seems to absorb less UV and additionally, females showed higher levels of skin damage than males (Zamzow 2004). The use of MAAs as a strategy of protection against UVR exposure in sea chub was suggested by Carrasco-Malio et al. (2014). In the Australian reef fish Pomacentrus amboinensis and Thalassoma lunare, MMAs act as a first line of defense against UVR-induced DNA damage (UVA-6.1 $\mathrm{W} \mathrm{m}^{-2}$, UVB- $13.4 \mathrm{~W} \mathrm{~m}^{-2}$ ). In $P$. amboinensis, the epidermal mucous absorbance was significantly higher in the UVB exposed juveniles when compared with the control (Braun et al. 2016). The mechanisms underlying the transport of MAAs into the mucous layer and regulation of MAAs content in mucous are poorly understood. Braun et al. (2016) suggested two plausible explanations for the increase in mucus absorbance observed in $P$. amboinensis. First, MMAs can be stored in tissues such as the gastrointestinal tract and gonads and then transferred by specific transporters, and accumulated in the mucous producing globet cells. On the other hand, MAAs originating from bacteria with a functioning shikimate pathway can be potentially transferred into fish via the epidermal fish mucous (Braun et al. 2016). Juveniles of the reef fish Patagonotothen cornucola fed with a rich-UVAC diet showed a significant lower respiration rate than those fed with a poor-UVAC diet (Valinas and Helbling 2016). Cha et al. (2011) demonstrated how phlorotannins in zebrafish can have a significant photoprotective role during UVB exposure. Zebrafish embryos pretreated with these polyphenols, synthesized by algae, exhibited reduced hyperpigmentation, as well as UV-B-induced reactive oxygen species and nitric oxide levels, thus offering protection against UV-B-induced cell death (Cha et al. 2011).

\section{Interaction between UVR, environmental factors, and pollutants}

The anthropogenic impact of climate change (e.g., changing temperature and atmospheric $\mathrm{CO}_{2}$, precipitation, and ice melting) and other stressors on ecosystems are resulting in an increasingly difficult habitat for organisms. The health status of aquatic animals generally depends on a combination of several environmental factors, and where a disturbance in their tolerance limits occurs, they can become stressors (Schulte 2014). Indeed, recent evidence indicates that the deleterious effects of UVR may be enhanced by interactions with some environmental factors (e.g. increased temperature and hypoxia due to climate change) or pollution (Häder et al. 2015; Häder and Barnes 2019). The interaction between UVR and other stressors can increase the negative impact compared to UVR exposure alone, and can result in antagonistic, synergistic or additive effects that affect fish physiological status, growth or survival (Roberts et al. 2017).

The interactive effects of UVB radiation and temperature have been reported in a few studies. In zebrafish, UVB radiation and temperature (low $24{ }^{\circ} \mathrm{C}$ and high $30^{\circ} \mathrm{C}$ ) can disrupt embryonic metabolism, modulate immune system response and impair its embryonic development (Aksakal and Ciltas 2018). Low and high temperatures led to an increase in hatching time, development of malformations and mortality. Additionally, for both temperatures, an upregulation in oxidative stress (superoxide dismutase 1, catalase 1), heat shock protein 70 and immune-related (interleukin-1 beta, tumor necrosis factor alpha) genes was observed. Similar results were obtained in the presence of UVB at the control temperature $\left(28{ }^{\circ} \mathrm{C}\right)$. The combination of both stressors revealed that low and high temperatures have additive effects on top of the damaging effects of UVB during early development in zebrafish (Aksakal and Ciltas 2018). The authors suggested that the low temperature strengthens the sensitivity of zebrafish larvae to UVB exposure for two possible reasons: (1) a reduction in the enzyme- 
mediated DNA damage repair mechanism that can occur due to a retardation of overall biochemical reactions at low temperatures; and (2) delayed embryo/larvae development resulting from a prolonged exposure to UVB radiation (Aksakal and Ciltas 2018). The impact of both global warming and the increase in UVB radiation levels due to stratospheric ozone depletion was evaluated in Atlantic salmon juveniles. After 8 weeks of exposure, the effects of temperature and UVB were mainly additive, and the lowest complement-dependent bacteriolytic activity, hematocrit and plasma protein levels were observed when the fish were exposed simultaneously to both stressors, suggesting an innate immune system suppression (Jokinen et al. 2011). The combination of temperature and UVB can interact synergistically to suppress metabolism and increase the susceptibility to pathogens in mosquitofish (Gambusia holbrooki). The highest infection levels by the ciliated protozoan Ichtyhophthirius multifiliis were observed in fish exposed for 10 days to the highest UVB and temperature treatments (mean infection abundance-about 55 parasites per host), compared to the the infection levels of fish exposed to both stressors separately (high UVB-about 20 parasites per host; high temperature-about 20 parasites per host; and control—about 10 parasites per host), (Cramp et al. 2014).

The role of UVR interactions with other stressors in species survival and successful habitat selection and adaptation is still poorly studied. For example, a reduction in water transparency and/or an increase in water temperature can permit the establishment of the warm-water species largemouth bass (Micropterus salmoides) in the highly transparent cold waters of Lake Tahoe, California/Nevada. Such habitat invasion results in the higher tolerance of larvae to UVR and can reduce the population size of the native redside minnow (Richardsonius egregius) through predation or competition (Tucker and Williamson 2014). The interaction between temperature and UVB can determine the movement and the microhabitat selection of zebrafish. In an open field arena with a thermal gradient $\left(20-30{ }^{\circ} \mathrm{C}\right)$ and under-exposure to UVB (daily dose of $1.19 \mathrm{~kJ} \mathrm{~m}^{-2}$ ) during 3 weeks, fish avoided the temperature extremes compared to the control (Seebacher et al. 2016).

Groff et al. (2010) showed that DNA damage caused by UV exposure in tambaqui (Colossoma macropomum) erythrocytes can be enhanced by co- exposure to hypoxia conditions, most probably due to ROS generation under low dissolved oxygen levels in the water. Using a comet assay, the authors observed a significant increase in the damage index and damage frequency in tambaqui under normoxia and as a function of UVR exposure doses, compared to unexposed fish. However, a higher damage index and frequency in the erythrocytes was observed when the fish were co-exposed to UVR $\left(0.504 \mathrm{~W} \mathrm{~cm}^{-2} \mathrm{UVA}\right.$, $1.080 \mathrm{~W} \mathrm{~cm}^{-2} \mathrm{UVB}$ ) and hypoxia than when exposed only to the UVR (Groff et al. 2010).

UVR can enhance the toxicity of polycyclic aromatic hydrocarbons (PAHs) (Bridges et al. 2018). Photo-induced toxicity can increase the generation of ROS, and the subsequent increase of oxidative stress has been suggested as one of the mechanisms of PAH photo-toxicity in fish (Weinstein and Oris 1999). For example, the co-exposure of UVR (UVA: $1.31 \mathrm{~W} \mathrm{~m}^{-2}$; UVB: $0.11 \mathrm{~W} \mathrm{~m}^{-2}$ ) and anthracene (ANT) in bluegill sunfish liver microsomes resulted in oxidative stress through the increase in lipid peroxidation levels and superoxide anion production (Choi and Oris 2000). The authors measured malondialdehyde (MDA) nmoles produced in the liver microsomes exposed during $60 \mathrm{~min}$ to the following treatments: PAR, PAR + ANT, UVR, and UVR + ANT. No significant differences were observed in the produced MDA nmoles between the control (PAR) and the anthracene (PAR + ANT) treatments. Two times more MDA nmoles were produced in the presence of UVR (approx. 500 MDA nmol) when compared to PAR, but the highest number of MDA nmoles were observed in the presence of UVR and ANT (approx. 800 MDA nmol), (Choi and Oris 2000). The hatching rate success was reduced in mahi-mahi (Coryphaena hippurus) after $7 \mathrm{~h}$ of embryo exposure to both natural solar radiation (UVR) and a mixture of PAHs $\left(\mathrm{tPAH}_{50}\right.$, defined as the sum of the concentrations of 50 PAHs analytes present in the mixture), (Alloy et al. 2016). Similar hatching success percentages $(>80 \%)$ were observed between the control $\left(<10 \%\right.$ of natural solar UVR, $\left.0.4 \mu \mathrm{g} \mathrm{L}^{-1} \mathrm{tPAH}_{50}\right)$, UVR $\left(100 \%\right.$ of natural solar UVR, $0.4 \mu \mathrm{g} \mathrm{\textrm {L } ^ { - 1 }}$ tPAH $\left._{50}\right)$ and PAHs $(<10 \%$ of natural solar UVR, $>$ $\left.2.7 \mu \mathrm{g} \mathrm{L}^{-1} \mathrm{tPAH}_{50}\right)$ treatments. Nonetheless, a decrease in more than $50 \%$ in the hatching rate success was observed in the UVR and PAHs treatment ( $100 \%$ of natural solar UVR, $>2.7 \mu \mathrm{g} \mathrm{L}^{-1} \mathrm{tPAH}_{50}$ ). This decrease resulted in the delayed development in 
the co-exposed embryos, which may affect survival and later recruitment compared with the control embryos (Alloy et al. 2016).

The photo-induced toxicity of a mixture of PAHs was also evaluated in yellowtail kingfish (Seriola lalandi) during early development. Embryos coexposed to UVR and a mixture of PAHs showed an evident decrease in the hatching rate success when compared to those exposed to UVR or the mixture of PAHs alone. In the absence of UVR, no significant changes were observed in the hatching rate success when exposed to different concentrations of the mixture of PAHs (3.9-172 ng L ${ }^{-1}$ tPAHs), (Sweet et al. 2018). The cardiac function in the yellowtail kingfish embryos was affected by exposure to PAHs, where the exposed embryos showed an increase in the pericardial area and a higher incidence of cardiac arrhythmias and edema. However, the co-exposure of PAHs and UVR only increased the incidence of cardiac arrhythmias (Sweet et al. 2018). Synergistic effects between UVB and retene (7-isopropyl-1methylphenanthrene) were observed during early development in the whitefish (Coregonus lavaretus), as suggested by Häkkinen et al. (2003). In whitefish larvae exposed either to UVB radiation for two days (2.8 and $5.4 \mathrm{~kJ} \mathrm{~m}^{-2} \mathrm{~d}^{-1}$ ), or separately to different retene concentrations $\left(10,32\right.$ and $\left.100 \mu \mathrm{g} \mathrm{L}^{-1}\right)$, no significant mortality (max. $4 \%$ ) was observed. In the control group without exposure to any UVB or retene, the larvae survival was $100 \%$. However, when the larvae were exposed to UVB $\left(2.8\right.$ and $\left.5.4 \mathrm{~kJ} \mathrm{~m}^{-2} \mathrm{~d}^{-1}\right)$ together with retene ( 32 and $100 \mu \mathrm{g} \mathrm{L}^{-1}$ ), more than $90 \%$ of the larvae died after exposure. Furthermore, signs of hypoxia and behavioral changes (uncontrolled spiral swimming, fish remained at the bottom of the bowl) were observed in the larvae exposed simultaneously to both stressors. No changes in behavior occurred in larvae exposed to UVB or retene alone (Häkkinen et al. 2003). Severe lesions in the skin and liver fish were exhibited by the larvae co-exposed to UVB and retene. The histopathological changes observed on the skin comprised loss of membrane integrity, uplifting of the epidermis due to sloughing and vacuolization, and the appearance of necrotic cells in the epidermis showing shrunken nuclei. Interestingly, the number of neutral and acidic mucous producing cells increased by around $60 \%$ in the epidermis of the whitefish larvae exposed to UV-B and retene $\left(32 \mathrm{mg} \mathrm{L}^{-1}\right)$. Such an increase may be part of a protective mechanism against the retene toxicity caused by UVB. In the liver, whitefish larvae exposed to UVB and 10 or $32 \mathrm{mg} \mathrm{L}^{-1}$ retene showed hepatocytes containing necrotic nuclei (Häkkinen et al. 2003).

Gevertz et al. (2012) demonstrated that the nonnative bluegill sunfish is more susceptible than the Lake Tahoe native Lahontan redside minnow to the harmful effects of combined exposure to UVB radiation and fluoranthene (FLU). When exposed only to UVB, the native redside minnow displayed more tolerance $\left(\mathrm{LD}_{50}, 28.0 \mathrm{~W} \mathrm{~cm} \mathrm{Ch}^{-2} \mathrm{UVB}\right)$ to the radiation than the non-native bluegill sunfish $\left(\mathrm{LD}_{50}\right.$, $\left.4.6 \mathrm{~W} \mathrm{~cm}^{-2} \mathrm{~h}^{-1} \mathrm{UVB}\right)$. Co-exposure to UVB and FLU reduced the $L_{50}$ significantly in the native Lahontan redside minnow $\left(\mathrm{LD}_{50}, 15.4 \mathrm{~W} \mathrm{~cm}^{-2} \mathrm{~h}^{-1}\right.$ UVB). Furthermore, damage to the skin that resulted from the combination of UVR and FLU $\left(50 \mathrm{ng} \mathrm{L}^{-1}\right)$ was more pronounced in the non-native species as shown by the transmission electron microscopy-ultrastructural tissue examination (Gevertz and Oris 2014).

Manufactured nano-scale titanium dioxide particles (nano- $\mathrm{TiO}_{2}$ ) are present in a broad range of products, and are usually found in personal care products including cosmetics and sunscreens. The phototoxicity of the nanomaterials in Japanese medaka was shown by exposure of the larvae to both nano- $\mathrm{TiO}_{2}$ particles and UVA radiation. High mortality was observed in the larvae co-exposed to both stressors. Under the simultaneous exposure to both nano- $\mathrm{TiO}_{2}$ and UVA, the photo-toxicity of nano-TiO2 increased by two powers of magnitude in the medaka larvae (Ma et al. 2012).

\section{Conclusions}

Exposure to ultraviolet radiation (UVA and mainly UVB) is harmful during all stages of a fish life cycle, from egg fertilization to the adult phase (Fig. 3). This current review summarizes results reported in numerous studies on fresh and seawater fish species.

Short and long-term exposure to UVR can induce damage to fish at molecular, cellular and/or tissue levels. During early development (eggs, embryos and larvae), an increase in mortality and a high incidence of developmental abnormalities are the most reported negative effects. The majority of these abnormalities include spinal/notochord deformities, enlarged 

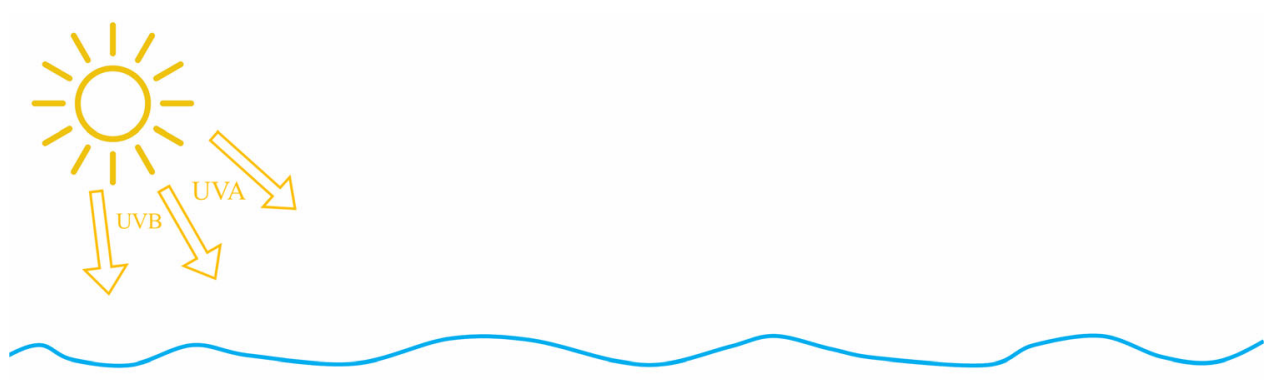

Early development stages

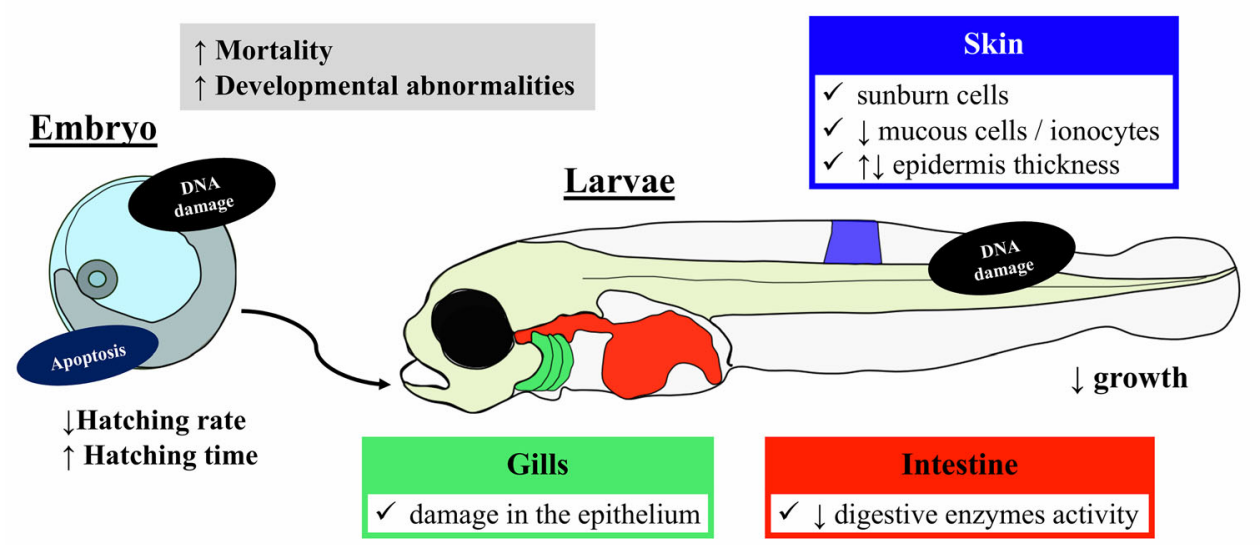

$\underline{\text { Juveniles and adults }}$

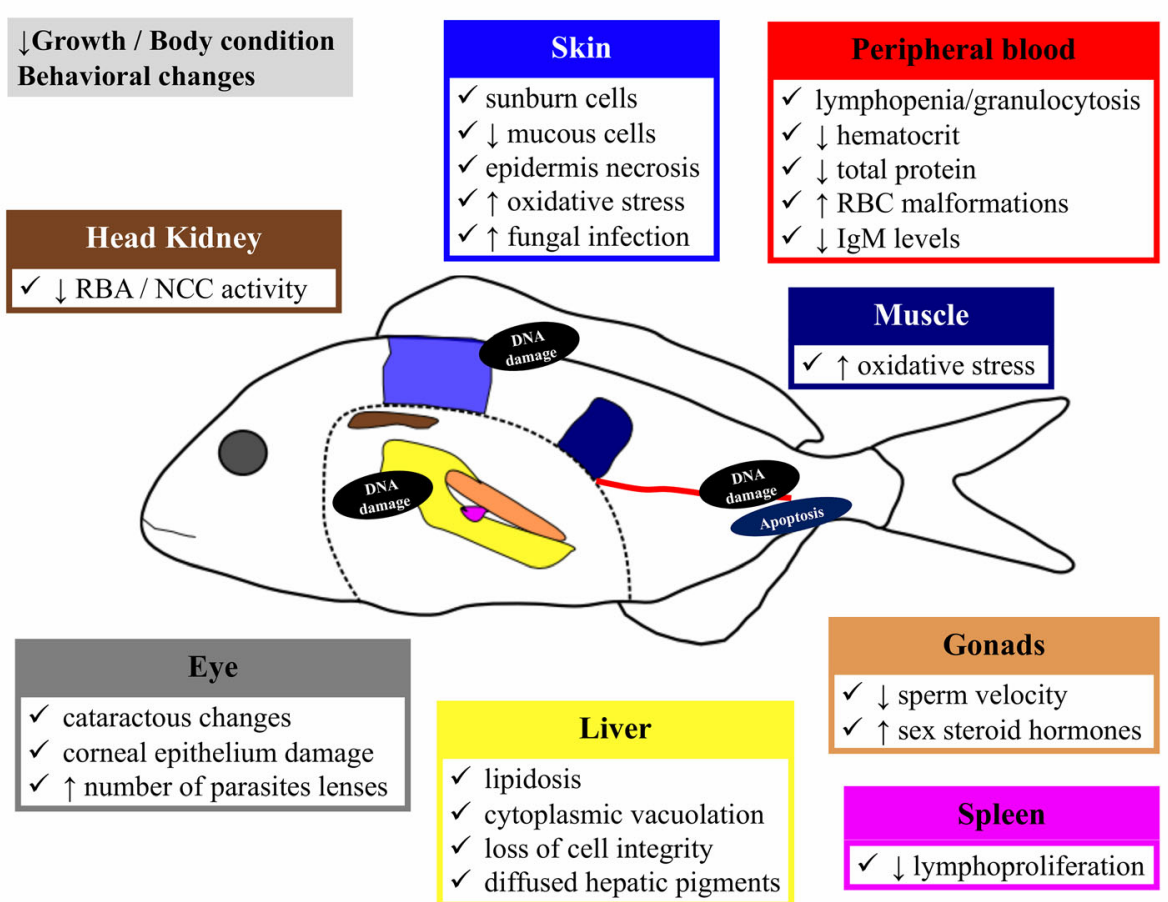


4 Fig. 3 Schematic representation of the harmful effects of solar UVR exposure in the fish development stages: a embryos/larvae and $\mathbf{b}$ juveniles/adults

pericardial sacs and the presence of blisters in the yolk. A remarkable decrease in the hatching success and a more prolonged hatching time has also been documented. Loss of normal swimming capacity and low escape performance from predators in fish larvae are the most evident behavioral changes. The skin and gills seem to be the most affected tissues in larvae exposed to UVR (Fig. 3a). Lesions include structural and functional changes in the following tissues: sunburn on the skin, changes in epidermis thickness, a decrease in number and size of mucous cells, deformation in the ionocytes structure, and damage in the epithelium tissue of the gills. In short, under UVR exposure, the following biological functions can be compromised: (1) the role of the skin as the first line of defense against pathogenic microorganisms in the surrounding water; (2) the skin and gills osmoregulatory capacity; (3) the digestive physiology and (4) the immune response.

In juveniles and adults, growth reduction and loss of body condition were described after short- or longterm UVB exposure, probably influenced by physiological and metabolic changes incurred by exposure (Fig. 3b). Behavioral changes following UVR exposure were evident in these life cycle stages and included feeding behavior, loss of appetite, restless behavior, changes in swimming activity and low predatory performance. Nevertheless, the mechanisms underlying how fish perceive UVR and how these mechanisms are triggered are poorly understood and should be further explored in the future. Several tissues/organs are negatively affected by both UVA and UVB exposure. These effects include: sunburn on skin, hyperpigmentation, a decrease in mucous production and club cells, inflammation, appearance of necrotic tissue in the epidermis, damage in corneal epithelium of the eyes, cataractous changes, higher incidence in number of parasites in the eye lenses, loss of cell integrity in the liver, lipidosis, cytoplasmic vacuolation, inflammatory lymphocytic infiltration, and high incidence of morphological malformations in red blood cells. A potential risk from UVR exposure on fish health is evidenced by the disruption in both innate and acquired immune systems, which can decrease the resistance of fish to diseases. Impairment of molecular and cellular processes was evidenced in all development stages and in different tissues (Fig. 3). Such damage is characterized by an increase in the extent of DNA damage and apoptosis and changes in the antioxidant status. Information on the overall transcriptional changes in these tissues/organs, including those involved in the immune system, is scarce. A key challenge in the future will be to establish the overall molecular mechanisms involved in the different responses of these tissues/organs to the detrimental effects of UVB and UVA exposure. Large-scale transcriptome analysis in these tissues/ organs under different cumulative doses of UVR will give new insights about the direct and indirect photochemical pathways that characterize UVB-induced damage in fish. Moreover, there is limited knowledge on the strategies used by fish to reduce the impact of UVR, and analysis of mucous proteome from different species could provide new insights on the photo-protective mechanisms.

Current evidence suggests that the destruction of stratospheric ozone, climate change and interaction with other environmental and anthropogenic stressors can lead to significant changes in underwater UVR levels. These changes may lead to more damaging effects on fish species in inland and ocean waters, which may have an impact on the fisheries and aquaculture sectors. One of the challenges in the near future will be to predict how the fish will cope with these changes, and if they will be able to adapt to future levels of UVR. There are still few studies describing how UV-detrimental effects are enhanced by interactions between UVR and temperature or pollutants; more effort should be made in light of future climate-change scenarios and the presence of both persistent and emerging contaminants. A better understanding on the harmful effects of UVR and how to reduce the impact of UVR on fish is important to mitigate ecological problems, such as predicting invasive species and their impact on native species populations. Such knowledge can also be used to improve fish aquaculture production by adjusting the fish rearing conditions in the offshore cages to minimize the damage caused by UVR, as well as formulating feed with UVAs. 


\section{Compliance with ethical standards}

Conflict of interest The authors declare no conflict of interest.

Open Access This article is licensed under a Creative Commons Attribution 4.0 International License, which permits use, sharing, adaptation, distribution and reproduction in any medium or format, as long as you give appropriate credit to the original author(s) and the source, provide a link to the Creative Commons licence, and indicate if changes were made. The images or other third party material in this article are included in the article's Creative Commons licence, unless indicated otherwise in a credit line to the material. If material is not included in the article's Creative Commons licence and your intended use is not permitted by statutory regulation or exceeds the permitted use, you will need to obtain permission directly from the copyright holder. To view a copy of this licence, visit http://creativecommons.org/licenses/by/4.0/.

\section{References}

Agustí S, Llabrés M, Carreja B, Fernandez M, Duarte CM (2015) Contrasting sensitivity of marine biota to UV-B radiation between southern and northern hemispheres. Estuar Coast 38:1126-1133

Ahmed FE, Setlow RB (1993) Ultraviolet radiation-Induced DNA damage and its photorepair in the skin of the platyfish xiphophorus. Cancer Res 53:2249-2255

Aksakal FI, Ciltas A (2018) The impact of ultraviolet B (UV-B) radiation in combination with different temperatures in the early life stage of zebrafish (Danio rerio). Photochem Photobiol Sci 17:35-41

Alemanni ME, Lozada M, Zagarese HE (2003) Assessing sublethal effects of ultraviolet radiation in juvenile rainbow trout (Oncorhynchus mykiss). Photochem Photobiol Sci 2:867-870

Alloy M, Baxter D, Stieglitz J, Mager E, Hoenig R, Benetti D, Grosell M, Oris J, Roberts A (2016) Ultraviolet radiation enhances the toxicity of deepwater horizon oil to mahimahi (Coryphaena hippurus) embryos. Environ Sci Technol 50:2011-2017

Applegate LA, Ley RD (1988) Ultraviolet radiation-induced lethality and repair of pyrimidine dimers in fish embryos. Mutat Res 198:85-92

Armstrong TN, Reimschuessel R, Bradley BP (2002) DNA damage, histologial changes and DNA repair in larval Japanese medaka (Oryzias latipes) exposed to ultraviolet-B radiation. Aquat Toxicol 58:1-14

Arts MT, Browman HI, Jokinen EI, Kuhn PS, Skiftesvik AB (2010) Effects of UV radiation and diet on polyunsaturated fatty acids in the skin, ocular tissue and dorsal muscle of Atlantic Salmon (Salmo salar) held in outdoor rearing tanks. Photochem Photobiol 86:909-919

Aycock RL, Bradshaw AC, Sage EH, Starcher B (2004) Development of UV-induced squamous cell carcinomas is suppressed in the absence of SPARC. J Invest Dermatol 123:592-599
Banerjee S, Leptin M (2014) Systemic response to ultraviolet radiation involves induction of leukocytic IL-1 beta and inflammation in zebrafish. J Immunol 193:1408-1415

Barnes PW, Williamson CE, Lucas RM, Robinson SA, Madronich S, Paul ND, Bornman JF, Bais AF, Sulzberger B, Wilson SR, Andrady AL, McKenzie RL, Neale PJ, Austin AT, Bernhard GH, Solomon KR, Neale RE, Young PJ, Norval M, Rhodes LE, Hylander S, Rose KC, Longstreth J, Aucamp PJ, Ballaré CL, Cory RM, Flint SD, de Gruijl FR, Häder D, Heikkilä AM, Jansen MAK, Pandey KK, Robson TM, Sinclair CA, Wängberg S, Worrest RC, Yazar S, Young AR, Zepp RG (2019) Ozone depletion, ultraviolet radiation, climate change and prospects for a sustainable future. Nat Sustain 2:569-579

Beland F, Browman HI, Rodriguez CA, St-Pierre JF (1999) Effect of solar ultraviolet radiation $(280-400 \mathrm{~nm})$ on the eggs and larvae of Atlantic cod (Gadus morhua). Can J Fish Aquat Sci 56(6):1058-1067

Bell GM, Hoar WS (1950) Some effects of ultraviolet radiation on sockeye salmon eggs and alevins. Can J Res 28(1):35-43

Blazer VS, Fabacher DL, Little EE, Ewing MS, Kocan KM (1997) Effects of ultraviolet-B radiation on fish: histologic comparison of a UVB-sensitive and a UVB-tolerant species. J Aquat Anim Health 9:132-143

Boily V, Bertolo A, Magnan P, Martinoli MG, Therien HM (2011) The effects of UVR irradiance and spectral composition on yellow perch (Perca flavescens) larvae survival. Aquat Sci 73:345-354

Braun C, Reef R, Siebeck UE (2016) Ultraviolet absorbing compounds provide a rapid response mechanism for UV protection in some reef fish. J Photochem Photobiol B 160:400-407

Bridges KN, Krasnec MO, Magnuson JT, Morris JM, Gielazyn ML, Chavez JR, Roberts AP (2018) Influence of variable ultraviolet radiation and oil exposure duration on survival of red drum (Sciaenops ocellatus) larvae. Environ Toxicol Chem 37:2372-2379

Browman HI, Vetter RD, Rodriguez CA, Cullen JJ, Davis RF, Lynn E, St Pierre JF (2003) Ultraviolet (280-400 nm)-induced DNA damage in the eggs and larvae of Calanus finmarchicus G. (Copepoda) and Atlantic cod (Gadus morhua). Photochem Photobiol 77:397-404

Bullock AM (1982) The pathological effects of ultraviolet-radiation on the epidermis of teleost fish with reference to the solar-radiation effect in higher animals. Proc R Soc Edinb B 81:199-210

Bullock AM (1984) The skin response of fish to ultraviolet radiation: a histological study. Dissertation, University of Stirling

Bullock AM (1988) Solar ultraviolet radiation: A potential environmental hazard in the cultivation of farmed finfish. In: Muir JF, Roberts RJ (eds) Recent advances in aquaculture, vol 3. Croom Helm, London, pp 139-224

Bullock AM, Coutts RR (1985) The impact of solar ultravioletradiation upon the skin of rainbow-trout, Salmo gairdneri Richardson, farmed at high-altitude in Bolivia. J Fish Dis $8: 263-272$

Buma AGJ, Boelen P, Jeffrey WH (2003) UVR-induced DNA damage in aquatic organisms. In: Helbling EW, Zagarese $\mathrm{H}$ 
(eds) UV effects in aquatic organisms and ecosystems. The Royal Society of Chemistry, London

Carefoot TH, Harris M, Taylor BE, Donovan D, Karentz D (1998) Mycosporine-like amino acids: possible UV protection in eggs of the sea hare Aplysia dactylomela. Mar Biol 130:389-396

Carefoot TH, Karentz D, Pennings SC, Young CL (2000) Distribution of mycosporine-like amino acids in the sea hare Aplysia dactylomela: effect of diet on amounts and types sequestered over time in tissues and spawn. Comp Biochem Phys C 126:91-104

Carrasco-Malio A, Diaz M, Mella M, Montoya MJ, Miranda A, Landaeta MF, Sanchez G, Hidalgo ME (2014) Are the intertidal fish highly resistant to UV-B radiation? A study based on oxidative stress in Girella laevifrons (Kyphosidae). Ecotox Environ Safe 100:93-98

Cha SH, Ko CI, Kim D, Jeon YJ (2011) Protective effects of phlorotannins against ultraviolet $\mathrm{B}$ radiation in zebrafish (Danio rerio). Vet Dermatol 23:51-E12

Charron RA, Fenwick JC, Lean DRS, Moon TW (2000) Ultraviolet-B radiation effects on antioxidant status and survival in the zebrafish, Brachydanio rerio. Photochem Photobiol 72:327-333

Choi J, Oris JT (2000) Evidence of oxidative stress in bluegill sunfish (Lepomis macrochirus) liver microsomes simultaneously exposed to solar ultraviolet radiation and anthracene. Environ Toxicol Chem 19:1795-1799

Cramp RL, Reid S, Seebacher F, Franklin CE (2014) Synergistic interaction between UVB radiation and temperature increases susceptibility to parasitic infection in a fish. Biol Lett 10:20140449

Crutzen PJ, Arnold F (1986) Nitric acid cloud formation in the cold Antarctic stratosphere: a major cause for the springtime "ozone hole". Nature 324:651-655

Cullen AP, Monteithmcmaster CA (1993) Damage to the rainbow-trout (Oncorhyncus mykiss) lens following an acute dose of UVB. Curr Eye Res 12:97-106

Cullen AP, Monteithmcmaster CA, Sivak JG (1994) Lenticular changes in rainbow trout following chronic exposure to uvradiation. Curr Eye Res 13:731-737

Dahms HU, Lee JS (2010) UV radiation in marine ectotherms: molecular effects and responses. Aquat Toxicol 97:3-14

Dethlefsen V, von Westernhagen H, Tug H, Hansen PD, Dizer H (2001) Influence of solar ultraviolet-B on pelagic fish embryos: osmolality, mortality and viable hatch. Hel Mar Res 55:45-55

Dong Q, Svoboda K, Tiersch TR, Monroe WT (2007) Photobiological effects of UVA and UVB light in zebrafish embryos: evidence for a competent photorepair system. J Photochem Photobiol B 88:137-146

Doughty MJ, Cullen AP, Monteith-McMaster CA (1997) Aqueous humour and crystalline lens changes associated with ultraviolet radiation or mechanical damage to corneal epithelium in freshwater rainbow trout eyes. J Photochem Photobiol B 41:165-172

Dunlap WC, Williams DM, Chalker BE, Banaszak AT (1989) Biochemical photoadaptation in vision-uv-absorbing pigments in fish eye tissues. Comp Biochem Phys B 93:601-607

Esteban MA (2012) An overview of the immunological defenses in fish skin. ISRN Immun 2012:1-29
Esteban MA, Cerezuela R (2015) Fish mucosal immunity: skin. In: Beck BH, Peatman E (eds) Mucosal health in aquaculture. Academic Press, Cambridge, pp 67-92

Fabacher DL, Little EE (1995) Skin component may protect fishes from ultraviolet-B radiation. Environ Sci Pollut R 2:30-32

Fukunishi Y, Masuda R, Yamashita Y (2006) Ontogeny of tolerance to and avoidance of ultraviolet radiation in red sea bream Pagrus major and black sea bream Acanthopagrus schlegeli. Fish Sci 72:356-363

Fukunishi Y, Masuda R, Yamashita Y (2010) Exposure of eggs to solar UV-B leads to reduced hatching rates in two sparid fishes, red sea bream Pagrus major and black sea bream Acanthopagrus schlegeli. J Fish Biol 76:734-741

Fukunishi Y, Browman HI, Durif CMF, Bjelland RM, Skiftesvik AB (2012) Effect of sub-lethal exposure to ultraviolet radiation on the escape performance of Atlantic Cod Larvae (Gadus morhua). PLoS ONE 7:1-6

Fukunishi Y, Browman HI, Durif CMF, Bjelland RM, Shema SD, Fields DM, Skiftesvik AB (2013) Sub-lethal exposure to ultraviolet radiation reduces prey consumption by Atlantic cod larvae (Gadus morhua). Mar Biol 160:2591-2596

García-Huidobro MR, Aldana M, Duarte C, Galban-Malagon C, Pulgar J (2017) Seawater-temperature and UV-radiation interaction modifies oxygen consumption, digestive process and growth of an intertidal fish. Mar Environ Res 129:408-412

Gerhardt KE, Wilson MI, Greenberg BM (1999) Tryptophan photolysis leads to a UVB-induced $66 \mathrm{kDa}$ photoproduct of ribulose-1,5-bisphosphate carboxyIase/oxygenase (rubisco) in vitro and in vivo. Photochem Photobiol 70(1):49-56

Gevertz AK, Oris JT (2014) Microscopic examination of skin in native and nonnative fish from Lake Tahoe exposed to ultraviolet radiation and fluoranthene. Aquat Toxicol 147:151-157

Gevertz AK, Tucker AJ, Bowling AM, Williamson CE, Oris JT (2012) Differential tolerance of native and nonnative fish exposed to ultraviolet radiation and fluoranthene in Lake Tahoe (California/Nevada), USA. Environ Toxic Chem 31:1129-1135

Gomez D, Sunyer JO, Salinas I (2013) The mucosal immune system of fish: The evolution of tolerating commensals while fighting pathogens. Fish Shellfish Immun 35:1729-1739

Görner H (1994) Photochemistry of DNA and related biomolecules: quantum yields and consequences of photoionization. J Photochem Photobiol 26:117-139

Groff AA, da Silva J, Nunes EA, Ianistcki M, Guecheva TN, de Oliveira AM, de Oliveira CPF, Val AL, Henriques JAP (2010) UVA/UVB-induced genotoxicity and lesion repair in Colossoma macropomum and Arapaima gigas Amazonian fish. J Photochem Photobiol B 99:93-99

Häder DP, Barnes PW (2019) Comparing the impacts of climate change on the responses and linkages between terrestrial and aquatic ecosystems. Sci Total Environ 682:239-246

Häder DP, Porst M, Santas R (1998) Photoinhibition by solar radiation in the Mediterranean alga Peyssonnelia squamata measured on site. Plant Ecol 139:167-175 
Häder DP, Kumar HD, Smith RC, Worrest RC (2007) Effects of solar UV radiation on aquatic ecosystems and interactions with climate change. Photochem Photobiol Sci 6:267-285

Häder DP, Helbling EW, Williamson CE, Worrest RC (2011) Effects of UV radiation on aquatic ecosystems and interactions with climate change. Photochem Photobiol Sci 10:242-260

Häder DP, Williamson CE, Wangberg SA, Rautio M, Rose KC, Gao KS, Helbling EW, Sinha RP, Worrest R (2015) Effects of UV radiation on aquatic ecosystems and interactions with other environmental factors. Photochem Photobiol Sci 14:108-126

Häkkinen J, Vehniäinen E, Ylönen O, Heikkila J, Soimasuo M, Kaurola J, Oikari A, Karjalainen J (2002) The effects of increasing UV-B radiation on pigmentation, growth and survival of coregonid embryos and larvae. Environ Biol Fish 64:451-459

Häkkinen J, Vehniäinen E, Oikari A (2003) Histopathological responses of newly hatched larvae of whitefish (Coregonus lavaretus s.1.) to UV-B induced toxicity of retene. Aquat Toxicol 63:159-171

Häkkinen J, Vehniäinen E, Oikari A (2004) High sensitivity of northern pike larvae to UV-B but no UV-photoinduced toxicity of retene. Aquat Toxicol 66:393-404

Hart RW, Setlow RB (1974) Correlation between deoxyribonucleic-acid excision-repair and life-span in a number of mammalian-species. Proc Natl Acad Sci USA 71:2169-2173

Helbling EW, Gao KS, Goncalves RJ, Wu HY, Villafane VE (2003) Utilization of solar UV radiation by coastal phytoplankton assemblages off SE China when exposed to fast mixing. Mar Ecol Prog Ser 259:59-66

Hinrichs MA (1938) The microscopic anatomy of twins and double monsters of Fundulus heteroclitus. Physiol Zool 11:155-157

Hinrichs MA, Genther IT (1931) Ultra-violet radiation and the production of twins and double monsters. Physiol Zool 4:461-485

Holmquist LM, Ray AM, Bancroft BA, Pinkham N, Webb MAH (2014) Effects of ultraviolet-b radiation on woundfin embryos and larvae with application to conservation propagation. J Fish Wildl Manag 5:87-98

Holtby LB, Bothwell ML (2008) Effects of solar ultraviolet radiation on the behaviour of juvenile coho salmon (Oncorhynchus kisutch): avoidance, feeding, and agonistic interactions. Can J Fish Aquat Sci 65:701-711

Huff DD, Grad G, Williamson CE (2004) Environmental constraints on spawning depth of yellow perch: the roles of low temperature and high solar ultraviolet radiation. Trans Am Fish Soc 133:718-726

Hunter JR, Taylor JH, Moser HG (1979) Effect of ultravioletirradiation on eggs and larvae of the Northern Anchovy, Engraulis mordax, and the Pacific Mackerel, Scomber japonicus, during the embryonic stage. Photochem Photobiol 29:325-338

Hunter JR, Kaupp SE, Taylor JH (1981) Effects of solar and artificial ultraviolet-b radiation on larval Northern Anchovy, Engraulis mordax. Photochem Photobiol 34:477-486

Huovinen PS, Goldman CR (2000) Inhibition of phytoplankton production by UV-B radiation in clear subalpine Lake
Tahoe, California-Nevada. Int Ver Theor Ange 27:157-160

Huovinen PS, Penttila H, Soimasuo MR (2003) Spectral attenuation of solar ultraviolet radiation in humic lakes in Central Finland. Chemosphere 51:205-214

Hurem S, Fraser TWK, Gomes T, Mayer I, Christensen T (2018) Sub-lethal UV radiation during early life stages alters the behaviour, heart rate and oxidative stress parameters in zebrafish (Danio rerio). Ecotoxicol Environ Safe 166:359-365

Jokinen IE, Salo HM, Markkula SE, Aaltonen TM, Immonen AK (2000) Effects of ultraviolet light on immune parameters of the roach. Toxicol Lett 112:303-310

Jokinen IE, Salo HM, Markkula SE, Immonen AK, Aaltonen TM (2001) Ultraviolet B irradiation modulates the immune system of fish (Rutilus rutilus, Cyprinidae) part III: Lymphocytes. Photochem Photobiol 73:505-512

Jokinen IE, Markkula ES, Salo HM, Kuhn P, Nikoskelainen S, Arts MT, Browman HI (2008) Exposure to increased ambient ultraviolet $\mathrm{B}$ radiation has negative effects on growth, condition and immune function of juvenile Atlantic salmon (Salmo salar). Photochem Photobiol 84:1265-1271

Jokinen IE, Salo HM, Markkula E, Rikalainen K, Arts MT, Browman HI (2011) Additive effects of enhanced ambient ultraviolet $\mathrm{B}$ radiation and increased temperature on immune function, growth and physiological condition of juvenile (parr) Atlantic Salmon, Salmo salar. Fish Shellfish Immun 30:102-108

Kaweewat K, Hofer R (1997) Effect of UV-B radiation on goblet cells in the skin of different fish species. J Photochem Photobiol B 41:222-226

Kazerouni EG, Khodabandeh S (2010) Effects of ultraviolet radiation on skin structure and ultrastructure in Caspian Sea Salmon, Salmo trutta caspius, during alevin stage. Toxicol Environl Chem 92:903-914

Kazerouni EG, Khodabandeh S (2011) Ionocyte immunolocalization and the effects of ultraviolet radiation on their abundance and distribution in the alenins of caspian Sea Salmon, Salmo trutta caspius. Cell J 13:45-54

Kazerouni EG, Franklin CE, Seebacher F (2016) UV-B radiation interacts with temperature to determine animal performance. Funct Ecol 30:584-595

Kazerouni EG, Franklin CE, Seebacher F (2017) Parental exposure modulates the effects of UV-B on offspring in guppies. Funct Ecol 31:1082-1090

Kieber DJ, Peake BM, Scully NM (2003) Reactive oxygen species in aquatic ecosystems. In: Helbling EW, Zagarese $\mathrm{H}$ (eds) UV effects in aquatic organisms and ecosystems. The Royal Society of Chemistry, London

Kouwenberg JHM, Browman HI, Cullen JJ, Davis RF, St-Pierre JF, Runge JA (1999) Biological weighting of ultraviolet $(280-400 \mathrm{~nm})$ induced mortality in marine zooplankton and fish. I. Atlantic cod (Gadus morhua) eggs. Mar Biol 134:269-284

Lawrence KP, Young AR, Diffey BL, Norval M (2019). The impact of solar ultraviolet radiation on fish: immunomodulation and photoprotective strategies. Fish Fish: 1-16

Lesser MP, Farrell JH, Walker CW (2001) Oxidative stress, DNA damage and p53 expression in the larvae of Atlantic 
cod (Gadus morhua) exposed to ultraviolet (290-400 nm) radiation. J Exp Biol 204:157-164

Llabrés M, Agustí S (2006) Picophytoplankton cell death induced by UV radiation: evidence for oceanic Atlantic communities. Limnol Oceanogr 51:21-29

Llabrés M, Agustí S (2010) Effects of ultraviolet radiation on growth, cell death and the standing stock of Antarctic phytoplankton. Aquat Microb Ecol 59:151-160

Llabrés M, Agustí S, Fernandez M, Canepa A, Maurin F, Vidal F, Duarte CM (2013) Impact of elevated UVB radiation on marine biota: a meta-analysis. Glob Ecol Biogeogr 22:131-144

Lowe C, GoodmanLowe G (1996) Suntanning in hammerhead sharks. Nature 383:677

Ma HB, Brennan A, Diamond SA (2012) Phototoxicity of $\mathrm{TiO}_{2}$ nanoparticles under solar radiation to two aquatic species: Daphnia magna and Japanese medaka. EnvironToxicol Chem 31:1621-1629

Madronich S, Mckenzie RL, Caldwell M, Bjorn LO (1995) Changes in ultraviolet-radiation reaching the earths surface. Ambio 24:143-152

Mahmoud UM, Mekkaw IAA, Sayed AEH (2009) Ultraviolet radiation-A $(366 \mathrm{~nm})$ induced morphological and histological malformations during embryogenesis of Clarias gariepinus (Burchell, 1822). J Photochem Photobiol B 95:117-128

Malloy KD, Holman MA, Mitchell D, Detrich HW (1997) Solar UVB-induced DNA damage and photoenzymatic DNA repair in Antarctic zooplankton. Proc Natl Acad Sci USA 94:1258-1263

Manek AK, Ferrari MCO, Sereda JM, Niyogi S, Chivers DP (2012) The effects of ultraviolet radiation on a freshwater prey fish: physiological stress response, club cell investment, and alarm cue production. Biol J Linn Soc 105:832-841

Markkula SE, Salo HM, Immonen AK, Jokinen EM (2005) Effects of short- and long-term ultraviolet B irradiation on the immune system of the common carp (Cyprinus carpio). Photochem Photobiol 81:595-602

Markkula SE, Salo HM, Rikalainen AK, Jokinen EI (2006) Different sensitivity of carp (Cyprinus carpio) and rainbow trout (Oncorhynchus mykiss) to the immunomodulatory effects of UVB irradiation. Fish Shellfish Immun 21:70-79

Markkula SE, Karvonen A, Salo H, Valtonen ET, Jokinen EI (2007) Ultraviolet B irradiation affects resistance of rainbow trout (Oncorhynchus mykiss) against bacterium Yersinia ruckeri and trematode Diplostomum spathaceum. Photochem Photobiol 83:1263-1269

Markkula E, Salo HM, Rikalainen K, Jokinen IE (2009) Longterm UVB irradiation affects the immune functions of carp (Cyprinus carpio) and rainbow trout (Oncorhynchus mykiss). Photochem Photobiol 85:347-352

Marlow H (2010) The effects of acute ultraviolet irradiation on zebrafish (Danio rerio) eye structure and lens protein composition. A report of a senior study, biochemistry. Dissertation, Maryville College

Mason DS, Schafer F, Shick JM, Dunlap WC (1998) Ultraviolet radiation-absorbing mycosporine-like amino acids (MAAs) are acquired from their diet by medaka fish (Oryzias latipes) but not by SKH-1 hairless mice. Comp Biochem Physiol A 120:587-598
McFadzen I, Baynes S, Hallam J, Beesley A, Lowe D (2000) Histopathology of the skin of UV-B irradiated sole (Solea solea) and turbot (Scophthalmus maximus) larvae. Mar Environ Res 50:273-277

McKenzie RL, Aucamp PJ, Bais AF, Bjorn LO, Ilyas M (2007) Changes in biologically-active ultraviolet radiation reaching the Earth's surface. Photochem Photobiol Sci 6:218-231

Mekkawy IAA, Mahmoud UM, Osman AG, Sayed AE (2010) Effects of ultraviolet A on the activity of two metabolic enzymes, DNA damage and lipid peroxidation during early developmental stages of the African catfish, Clarias gariepinus (Burchell, 1822). Fish Physiol Biochem 36:605-626

Michael KJ, Veal CJ, Nunez M (2012) Attenuation coefficients of ultraviolet and photosynthetically active wavelengths in the waters of Heron Reef, Great Barrier Reef, Australia. Mar Freshwater Res 63:142-149

Mitchell DL, Nairn RS (1989) The biology of the (6-4) photoproduct. Annu Rev Photochem Photobiol 49:805-819

Mitchell DL, Scoggins JT, Morizot DC (1993) DNA-repair in the variable platyfish (Xiphophorus variatus) irradiated invivo with ultraviolet-B light. Photochem Photobiol 58:455-459

Mitchell DL, Meador JA, Byrom M, Walter RB (2001) Resolution of UV-induced DNA damage in Xiphophorus fishes. Mar Biotechnol 3:S61-S71

Mitchell DL, Adams-Deutsch T, Olson MH (2008) Dose dependence of DNA repair in rainbow trout (Oncorhynchus mykiss) larvae exposed to UV-B radiation. Photochem Photobiol Sci 8:75-81

Mitchell DL, Fernandez AA, Nairn RS, Garcia R, Paniker L, Trono D, Thames HD, Gimenez-Conti I (2010) Ultraviolet A does not induce melanomas in a Xiphophorus hybrid fish model. Proc Natl Acad Sci USA 107:9329-9334

Mitchell DL, Fernandez AA, Garcia R, Paniker L, Lin K, Hanninen A, Zigelsky K, May M, Nuttall M, Lo HH, Person MD, Earley R (2014) Acute exposure to ultraviolet$\mathrm{B}$ radiation modulates sex steroid hormones and receptor expression in the skin and may contribute to the sex bias of melanoma in a fish model. Pigment Cell Melanoma Res 27:408-417

Molina MJ, Rowland FS (1974) Stratospheric sink for chlorofluoromethanes: chlorine atom-catalysed destruction of ozone. Nature 249:810-812

Nuñez ET, Sobrino C, Neale PJ, Ceinos RM, Du SJ, Rotllant J (2012) Molecular response to ultraviolet radiation exposure in fish embryos: implications for survival and morphological development. Photochem Photobiol 88:701-707

Olson MH, Colip MR, Gerlach JS, Mitchell DL (2006) Quantifying ultraviolet radiation mortality risk in bluegill larvae: effects of nest location. Ecol Appl 16:328-338

Olson MH, Adams-Deutsch T, Cassels KJ, Oliver AE, Mitchell DL (2008) Patterns of ultraviolet radiation exposure in bluegill nests over the course of the spawning season. Trans Am Fish Soc 137:1446-1454

Oren A, Gunde-Cimerman N (2007) Mycosporines and mycosporine-like amino acids: UV protectants or multipurpose secondary metabolites? FEMS Microbiol Lett 269:1-10 
Osman AGM, Koutb M, Sayed AEH (2010) Use of hematological parameters to assess the efficiency of quince $(C y$ donia oblonga Miller) leaf extract in alleviation of the effect of ultraviolet: a radiation on African catfish Clarias gariepinus (Burchell, 1822). J Photochem Photobiol B 99(1):1-8

Pasparakis C, Sweet LE, Stieglitz JD, Benetti DD, Casente CT, Roberts AP, Grosell M (2017) Combined effects of oil exposure, temperature and ultraviolet radiation on buoyancy and oxygen consumption of embryonic mahi-mahi, Coryphaena hippurus. Aquat Toxicol 191:113-121

Pasparakis C, Wang Y, Stieglitz JD, Benetti DD, Grosell M (2019) Embryonic buoyancy control as a mechanism of ultraviolet radiation avoidance. Sci Total Environ 651(2):3070-3078

Peng SJ, Liao HX, Zhou T, Peng SL (2017) Effects of UVB radiation on freshwater biota: a meta-analysis. Glob Ecol Biogeogr 26:500-510

Plack PA, Fraser NW, Grant PT, Middleton C, Mitchell AI, Thomson RH (1981) Gadusol, an enolic derivative of cyclohexane-1,3-dione present in the roes of cod and other marine fish-isolation, properties and occurrence compared with ascorbic-acid. Biochem J 199:741-747

Pulgar J, Lagos P, Maturana D, Valdes M, Aldana M, Pulgar VM (2015) Effect of UV radiation on habitat selection by Girella laevifrons and Graus nigra (Kyphosidae). J Fish Biol 86:812-821

Pulgar J, Waldisperg M, Galban-Malagon C, Maturana D, Pulgar VM, Aldana M (2017) UV radiation impacts body weight, oxygen consumption, and shelter selection in the intertidal vertebrate Girella laevifrons. Sci Total Environ 578:317-322

Rick IP, Mehlis M, Esser E, Bakker TCM (2014) The influence of ambient ultraviolet light on sperm quality and sexual ornamentation in three-spined sticklebacks (Gasterosteus aculeatus). Oecologia 174:393-402

Riemer U, Lamare MD, Peake BM (2007) Temporal concentrations of sunscreen compounds (Mycosporine-like Amino Acids) in phytoplankton and in the New Zealand krill, Nyctiphanes australis GO Sars. J Plank Res 29:1077-1086

Roberts AP, Alloy MM, Oris JT (2017) Review of the photoinduced toxicity of environmental contaminants. Comp Biochem Physiol C 191:160-167

Rothschild LJ (1999) The influence of UV radiation on protistan evolution. J Euk Microbiol 46:548-555

Rowland FS (2006) Stratospheric ozone depletion. Philos Trans R Soc 361:769-790

Rowland FS, Molina MJ (1975) Chlorofluoromethanes in the environment. Rev Geophys Space Phys 13:1-35

Rozema J, Björn LO, Bornman JF, Gaberšcik A, Häder DP, Trošt T, Germ M, Klische M, Groniger A, Sinha PP, Lebert M, He YY, Buffoni-Hall R, de Bakker NV, van de Staaij J, Meijkamp BB (2002) The role of UV-B radiation in aquatic and terrestrial ecosystems-an experimental and functional analysis of the evolution of UV-absorbing compounds. J Photochem Photobiol B 66:2-12

Salo HM, Aaltonen TM, Markkula SE, Jokinen EI (1998) Ultraviolet B irradiation modulates the immune system of fish (Rutilus rutilus, Cyprinidae). I. Phagocytes. Photochem Photobiol 67:433-437
Salo HM, Jokinen EI, Markkula SE, Aaltonen TM, Penttila HT (2000a) Comparative effects of UVA and UVB irradiation on the immune system of fish. J Photochem Photobiol B $56: 154-162$

Salo HM, Jokinen EI, Markkula SE, Aaltonen TM (2000b) Ultraviolet B irradiation modulates the immune system of fish (Rutilus rutilus, Cyprinidae) II: blood. Photochem Photobiol 71:65-70

Sandrini JZ, Trindade GS, Nery LEM, Marins LF (2009) Timecourse expression of DNA repair-related genes in hepatocytes of zebrafish (Danio rerio) after UV-B exposure. Photochem Photobiol 85:220-226

Saurabh S, Sahoo PK (2008) Lysozyme: an important defence molecule of fish innate immune system. Aqua Res 39:223-239

Sayed AEH (2018) UVA-induced DNA damage and apoptosis in red blood cells of the African Catfish Clarias gariepinus. Photochem Photobiol 94:158-164

Sayed AEH, Mitani H (2016) The notochord curvature in medaka (Oryzias latipes) embryos as a response to ultraviolet A irradiation. J Photochem Photobiol B 164:132-140

Sayed AEH, Mitani H (2017) Immunostaining of UVA-induced DNA damage in erythrocytes of medaka (Oryzias latipes). J Photochem Photobiol B 171:90-95

Sayed AEH, Ibrahim AT, Mekkawy IAA, Mahmoud UM (2007) Acute effects of ultraviolet-A radiation on African catfish Clarias gariepinus (Burchell, 1822). J Photochem Photobiol B 89:170-174

Sayed AEH, Abdel-Tawab HS, Hakeem SSA, Mekkawy IA (2013) The protective role of quince leaf extract against the adverse impacts of ultraviolet-A radiation on some tissues of Clarias gariepinus (Burchell, 1822). J Photochem Photobiol B 119:9-14

Sayed AEH, Watanabe-Asaka T, Oda S, Mitani H (2016) Apoptosis and morphological alterations after UVA irradiation in red blood cells of p53 deficient Japanese medaka (Oryzias latipes). J Photochem Photobiol B 161:1-8

Sayed AEH, Solimanm HAM, Mitani H (2019) UVA-induced neurotoxicity in Japanese medaka (Oryzias latipes). Photochem Photobiol Sci 18:71-79

Schlichter D, Fricke HW, Weber W (1986) Light harvesting by wavelength transformation in a symbiotic coral of the redsea twilight zone. Mar Biol 91:403-407

Schulte PM (2014) What is environmental stress? Insights from fish living in a variable environment. J Exp Biol 217:23-30

Seebacher F, Kazerouni EG, Franklin CE (2016) Ultraviolet B radiation alters movement and thermal selection of zebrafish (Danio rerio). Biol Lett 12:1-4

Setlow RB (1974) The wavelengths in sunlight effective in producing skin cancer: a theoretical analysis. Proc Natl Acad Sci USA 71(6):2169-2173

Setlow RB, Setlow JK (1962) Evidence that ultraviolet-induced thymine dimers in DNA cause biological damage. Proc Natl Acad Sci USA 48:1250-1257

Setlow RB, Woodhead AD, Grist E (1989) Animal-model for ultraviolet radiation-induced melanoma: platyfish swordtail hybrid. P Natl Acad Sci USA 86:8922-8926

Setlow RB, Grist E, Thompson K, Woodhead AD (1993) Wavelengths Effective in Induction of Malignant-Melanoma. Proc Natl Acad Sci USA 90:6666-6670 
Sharma JG, Chakrabarti R (2006) Effects of UV-B radiation on the gills of Catla catla during early development. Tox Environ Chem 88:367-371

Sharma JG, Masuda R, Tanaka M (2005) Ultrastructural study of skin and eye of UV-B irradiated ayu Plecoglossus altivelis. J Fish Biol 67:1646-1652

Sharma JG, Masuda R, Tanaka M (2007) Orientation behaviour of Pagrus major larvae exposed to UV-B radiation in laboratory conditions. Int J Radiat Biol 83:49-52

Sharma JG, Rao YV, Kumar S, Chakrabarti R (2010) Impact of UV-B radiation on the digestive enzymes and immune system of larvae of Indian major carp Catla catla. Int J Radiat Biol 86:181-186

Singh MK, Sharma J, Chakrabarti R (2013) Effect of UB-B radiation on the defence system of Labeo rohita (Actinopterygii: Cypriniformes: Cyprinidae) larvae and its modulation by seed of Devil's Horsewhip, achyranthes aspera. Acta Ichthyol Piscat 43:119-126

Sinha RP, Häder DP (2002) UV-induced DNA damage and repair: a review. Photochem Photobiol Sci 1:225-236

Steeger HU, Wiemer M, Freitag JF, Paul RJ (1999) Vitality of plaice embryos (Pleuronectes platessa) at moderate UV-B exposure. J Sea Res 42:27-34

Steeger HU, Freitag JF, Michl S, Wiemer M, Paul RJ (2001) Effects of UV-B radiation on embryonic, larval and juvenile stages of North Sea plaice (Pleuronectes platessa) under simulated ozone-hole conditions. Helgoland Mar Res 55:56-66

Subramani PA, Hameed B, Michael RD (2015) Effect of UV-B radiation on the antibody response of fish: implication on high altitude fish culture. J Photochem Photobiol B 143:1-4

Sucré E, Vidussi F, Mostajir B, Charmantier G, Lorin-Nebel C (2012) Impact of ultraviolet-B radiation on planktonic fish larvae: alteration of the osmoregulatory function. Aquat Toxicol 109:194-201

Sweet LE, Revill NT, Strzelecki J, Hook SE, Morris JM, Roberts AP (2018) Photo-induced toxicity following exposure to crude oil and ultraviolet radiation in 2 Australian fishes. Environ Toxicol Chem 37:1359-1366

Tedetti M, Sempere R (2006) Penetration of ultraviolet radiation in the marine environment. A review. Photochem Photobiol 82:389-397

Thoma F (1999) Light and dark in chromatin repair: repair of UV-induced DNA lesions by photolyase and nucleotide excision repair. EMBO J 18:6585-6598

Tucker AJ, Williamson CE (2014) The invasion window for warmwater fish in clearwater lakes: the role of ultraviolet radiation and temperature. Divers Distrib 20:181-192

Tucker AJ, Williamson CE, Rose KC, Oris JT, Connelly SJ, Olson MH, Mitchell DL (2010) Ultraviolet radiation affects invasibility of lake ecosystems by warm-water fish. Ecology 91:882-890

Uribe C, Folch H, Enriquez R, Moran G (2011) Innate and adaptive immunity in teleost fish: a review. Vet Med 56:486-503

Valinas MS, Helbling EW (2016) Metabolic and behavioral responses of the reef fish Patagonotothen cornucola to ultraviolet radiation: Influence of the diet. J Exp Mar Biol Ecol 474:180-184
Vargas J, Duarte C, Galban-Malagónac G, García-Huidobro MR, Aldana M, Pulgara J (2018) Refuge quality to cope with UV radiation affects energy allocation in an intertidal fish. Mar Pollut Bull 130:268-270

Vásquez P, Llanos-Rivera A, Castro LR, Fernandez C (2016) UV radiation effects on the embryos of anchoveta (Engraulis ringens) and common sardine (Strangomera bentincki) off central Chile. Mar Fresh Res 67:195-209

Vehniäinen ER, Häkkinen J, Oikari A (2003) Photoinduced lethal and sublethal toxicity of retene, a polycyclic aromatic hydrocarbon derived from resin acid, to coregonid larvae. Environm Toxicol Chem 22:2995-3000

Vehniäinen ER, Häkkinen JM, Oikari AOJ (2007) Responses to ultraviolet radiation in larval pike, Esox lucius, of two origins and ages. Boreal Environ Res 12:673-680

Vehniäinen ER, Vahakangas K, Oikari A (2012) UV-B exposure causes DNA damage and changes in protein expression in northern pike (Esox lucius) posthatched embryos. Photochem Photobiol 88:363-370

Vetter RD, Kurtzman A, Mori T (1999) Diel cycles of DNA damage and repair in eggs and larvae of northern anchovy, Engraulis mordax, exposed to solar ultraviolet radiation. Photochem Photobiol 69:27-33

Vincent WF, Neale PJ (2000) Mechanisms of UV damage to aquatic organisms. In: Demers SMS, Vernet M (eds) The effects of UV radiation in the marine environment. Cambridge University Press, Cambridge

Vitt S, Rahn AK, Drolshagen L, Bakker TCM, Scharsack JP, Rick IP (2017) Enhanced ambient UVB light affects growth, body condition and the investment in innate and adaptive immunity in three-spined sticklebacks (Gasterosteus aculeatus). Aquat Ecol 51:499-509

Weinstein JE, Oris JT (1999) Humic acids reduce the bioaccumulation and photoinduced toxicity of fluoranthene fish. Environ Toxicol Chem 18:2087-2094

Williamson CE, Stemberger RS, Morris DP, Frost TM, Paulsen SG (1996) Ultraviolet radiation in North American lakes: attenuation estimates from DOC measurements and implications for plankton communities. Limnol Oceanogr 41:1024-1034

Williamson CE, Neale PJ, Hylander S, Rose KC, Figueroa FL, Robinson SA, Häder DP, Wängberg SÅ, Worrest RC (2019) The interactive effects of stratospheric ozone depletion, UV radiation, and climate change on aquatic ecosystems. Photochem Photobiol Sci 18(3):717-746

Wilson MI, Greenberg BM (1993) Protection of the D1 photosystem II reaction center protein from degradation in ultraviolet radiation following adaptation of Brassica napus L. to growth in ultraviolet-B. Photochem Photobiol 57:556-563

Wilson MI, Ghosh S, Gerhardt KE, Holland N, Babu BS, Edelman M, Dumbroff EB, Greenberg BM (1995) In vivo photomodification of ribulose-1,5-bisphosphate carboxylase/oxygenase holoenzyme by ultraviolet-B radiation. Plant Physiol 109:221-229

Xiao X, de Bettignies T, Olsen YS, Agustí S, Duarte CM, Wernberg T (2015) Sensitivity and acclimation of three canopy-forming seaweeds to UVB radiation and warming. Plos One 10:1-17 
Yabu T, Ishibashi Y, Yamashita M (2003) Stress-induced apoptosis in larval embryos of Japanese flounder. Fish Sci 69:1218-1223

Ylönen I, Heikkila J, Karjalainen J (2004) Metabolic depression in UVB exposed larval coregonids. Ann Zool Fen 41:577-585

Zagarese HE, Williamson CE (2001) The implications of solar UV radiation exposure for fish and fisheries. Fish Fish 2:250-260

Zamzow JP (2003) Ultraviolet-absorbing compounds in the mucus of temperate Pacific tidepool sculpins: variation over local and geographic scales. Mar Ecol Prog Ser 263:169-175
Zamzow JP (2004) Effects of diet, ultraviolet exposure, and gender on the ultraviolet absorbance of fish mucus and ocular structures. Mar Biol 144:1057-1064

Zamzow JP (2007) Ultraviolet-absorbing compounds in the mucus of shallow-dwelling tropical reef fishes correlate with environmental water clarity. Mar Ecol Prog Ser 343:263-271

Zamzow JP, Losey GS (2002) Ultraviolet radiation absorbance by coral reef fish mucus: photo-protection and visual communication. Environ Biol Fish 63:41-47

Publisher's Note Springer Nature remains neutral with regard to jurisdictional claims in published maps and institutional affiliations. 